\title{
LANGUAGE LEARNING STRATEGIES
}

Prof. Marcela Lilian Jalo

Este trabajo corresponde a la investigación realizada en el marco de la adscripción a la Cátedra Planificación Didáctica y Práctica de la Enseñanza en Inglés

\section{INTRODUCTION}

If a principle guiding the goals and purposes of the school of the 2 Ist Century were to be chosen, undoubtedly the more accepted one among educators and researchers would be that education has to be directed to help students to learn how to learn. One of the functions of future education should be to promote the capacity of students to manage their own learning, to adopt a growing autonomy and to have intellectual and social tools that allow them continuous learning throughout their lives. In an increasingly open and complex society, there is a growing insistence on the fact that education should be directed to promote capacities and competences, not only closed knowledge or programmed techniques. In this sense, Fernando Savater (1997: 49-50) defending the necessity to develop those competences or open capacities places the ability to learn at the center of all educational projects. He said:

"Pues bien, sin duda la propia habilidad de aprender es una muy distinguida capacidad abierta, la más necesaria y humana quizá de todas ellas. Y cualquier plan de enseñanza bien diseñado ha de considerar prioritario este saber que nunca acaba y que posibilita todos los demás, cerrados o abiertos, sean los inmediatamente útiles a corto plazo o sean los buscadores de una excelencia que nunca se da por satisfecha.»

Briefly, this new culture of learning is characterized by three essential features: we are in the society of information, of multiple knowledge and of continuous learning. In this society, school is no longer the first source of knowledge for the students in many fields.

Our students need no more information -though they may certainly need it- but rather the capacity to organize and to interpret this information, to give it sense. And mainly what they will need as future citizens is the ability to search, to select and to 
interpret information. In the society of information and knowledge, the school can no longer provide all the relevant information, because this is much more flexible than school itself: what the school can and should do is to prepare students so that they may access and give sense to that information by providing and developing learning strategies that allow them to make a critical assimilation of information.

Within the framework of a constructivist approach to language teaching, in which the student -guided by the teacher- is the one who builds his own learning, I have chosen the topic of learning strategies since the use and the selection of appropriate strategies for each task is of great importance to achieve a successful and significant learning. Thus, the student will know what strategies he should use to solve a learning situation appropriately inside and outside the classroom. Our role as teachers is to build a space of significant teaching keeping in mind the learners' needs and interests to sustain motivation and where learners have the opportunity to build their knowledge according to their personal characteristics. To teach is not only to transmit information; it is to go beyond the given information building a new knowledge starting from all that is known. In turn, students should learn to integrate correctly what they already know with new situations. In this sense, the teacher should create opportunities to transfer the new knowledge to different contexts and help students to do it through the use of strategies.

Each student learns different versions of what we teach and it is necessary to take into account these diverse meanings. The learning of each individual is the result of his previous knowledge and of the personal interpretation that he makes of the new information. Therefore, the meanings given to what is taught are the individual and personal construction of each student. Considering the diversity of the students, the teacher should teach according to the characteristics of the group as such, and the students' personal characteristics: their interests, their concerns, their necessities and their ways of approaching knowledge using different languages (verbal, musical, visual, kinesthetic) and applying different strategies so that the learners have the opportunity to relate the new problems and the new information to what they already know, and to transfer it to new contexts.

The focus of my work is first, to investigate on learning strategies based on the idea of learner self-direction in the context of a communicative approach to language learning. I have also turned from examining learning processes to examining individual learners and in particular how their ways of learning can be different. Factors such as previous learning experience, cognitive style and motivation, as well as aptitude, age and personality 
may all affect an individual's learning style and strategies. Different styles of learners adopt different strategies for learning successfully.

Learner strategy research has focused on studying how learners use strategies and what the differences are between the strategies used by successful and unsuccessful learners. Vann and Abraham (1990) studied the strategies of unsuccessful language learners on a variety of different kinds of tasks and found that what distinguished unsuccessful learners was not the lack of appropriate strategies but the inability to choose the right strategy for the task. Thus, for effective learning to take place, what is important is the learners' ability to respond to the particular learning situation and to manage their learning in an appropriate way. Studies of successful and unsuccessful learners show that people who succeed in learning have developed a range of strategies from which they are able to select those that are the most appropriate for a particular problem.

Teachers can help by making students aware of such strategies, and encouraging their use. By encouraging students to become self-reliant, teachers will raise the quality of their classroom learning and make it easier for them to carry on learning after their course has finished.

As Wenden and Rubin claim (1987:8) "one of the leading educational goals of the research on learner strategies is an autonomous language learner, one who is equipped with the appropriate skills and strategies to learn a language in a self-directed way." As teachers we should be involved in teaching learners the techniques of learning a language and help them become aware of how and when to use strategies that will enable them become self-directed.

Through my research on the topics already stated, I have become aware of learners' different cognitive styles and of the different kinds of strategies students may use to achieve a task.

Learning strategies involve an ability to monitor the learning situation and respond accordingly. This means being able to assess the situation, to plan, to select appropriate skills, to sequence and co-ordinate them, to monitor or assess their effectiveness and to revise the plan when necessary. So, for example, guessing the meaning of a word or skimming a text are skills, but the learner has to be able to use them in a purposeful way when appropriate.

We must emphasise in conclusion that the issue of strategy use is complex, and there are no simple solutions to the questions of how to promote efficient employment of strategies. What is more significant is teachers' sensitivity to the ways in which their learners learn, their attitudes towards teaching their learners to think and to learn, and 
an awareness of the part their learners must play in taking control of their learning.

The process of education is one of the most important and complex of all human endeavors. A popular notion is that education is something carried out by one person, a teacher, standing in front of a class and transmitting information to a group of learners who are all willing and able to absorb it. This view, however, simplifies what is a highly complex process involving an intricate interplay between the learning process itself, the teacher's intentions and actions, the individual personalities of the learners, their culture and background, the learning environment and many other variables. The successful educator must be one who understands the complexities of the teaching-learning process and can draw upon this knowledge to act in ways which empower learners both within and beyond the classroom situation.

Most language teachers have experienced the frustration of investing endless amounts of energy in their students and getting very little response. We all have had groups who never did their homework, who were reluctant to use the target language in pair or group work, who did not learn from their mistakes, who did not listen to each other, who did not use opportunities to learn outside the classroom, and so on.

Such behavior very often stems from one common cause: the learners' over-reliance on the teacher. Even otherwise motivated learners may assume a passive role if they feel the teacher is in charge of everything that happens in the classroom.

It is essential to give students practical guidance on how to develop a sense of responsibility so that they will understand why and how they learn and be willing to take an active role in their learning. The task is not an easy one, as training learners for responsibility involves changing their attitudes.

This paper is organized into two parts:

PART I: gives the theoretical background and deals with some of the trends and issues emerging from the general educational field that have had an important influence on the topic of language learning strategies.

PART II: explores the pedagogical applications of the work on learning strategies to the classroom.

I have adopted Nunan's (1999) classification of learning strategies explaining and exemplifying each strategy. I have extracted the examples for each type of strategies from different textbooks I am presently using at Colegio Nacional 'Rafael Hernandez' and Escuela de Lenguas UNLP. As a teacher, I feel pleased to work with textbooks that 
include examples of strategy training and whose authors build strategy awareness into their materials.

\section{PARTI}

\section{THEORETICAL BACKGROUND}

\section{I.I Cognitive psychology}

1.2 Humanism and experiential psychology

I.3 Implications of the humanistic approach

I.4 Learner-centered education

1.5 Responsibility and autonomy

1.6 What can teachers do to promote learning?

\section{FOCUS ON THE LEARNER}

\subsection{Learner strategies}

2.2 Learner training

2.3 Learning strategies in second language acquisition

2.4 Language learning strategies

2.5 Cognitive and metacognitive strategies

\section{RESEARCH ON LEARNING STRATEGIES}

3.I The theory of learner training

\section{THEORETICAL BACKGROUND}

\section{I.I COGNITIVE PSYCHOLOGY}

As stated by Hamachek (1977), cognitive psychology is concerned with the way in which the human mind thinks and learns. Cognitive psychologists are interested in the mental processes that are involved in learning. This includes such aspects as how people build up and draw upon their memories and the ways in which they become involved in the process of learning.

In recent years cognitive psychology has had a considerable influence on language teaching methodology. In a cognitive approach, the learner is seen as an active participant in the learning process, using various mental strategies in order to sort out the system 
of the language to be learned. Learners are required to use their minds to observe, think, categorise and hypothesise and in this way, gradually work out how the language operates. Learners are engaged in formulating hypotheses in order to discover the rules of the target language. Errors are inevitable and are signs that learners are actively testing their hypotheses. For a while in the early 1970s there was great interest in applying this new Cognitive Approach to language teaching, and materials were developed with deductive (learners are given the rule and asked to apply it) and inductive (learners discover the rules from the examples and then practice it) grammar exercises. However, no language teaching method ever really developed directly from the Cognitive Approach; instead, a number of 'innovative methods' emerged.

At one extreme are information theorists who have drawn the analogy of the brain as a highly complex computer and who seek to explain its workings in terms of rules and models of how different aspects of learning take place. Examples of this approach can be seen in work on artificial intelligence systems and, particularly, in models of memory and reading processes. Cognitive psychologists who take this approach to learning are mainly concerned with the way in which people take in information, process it and act upon it. Factors such as attention, perception and memory become the focus of their work. The main emphasis in this approach is placed upon the conception of intelligent behaviour as something flexible; that is, people can become more intelligent and schools can play a part in this. This view has powerful implications for language teachers. If we hold such a view, we then believe that we can help all learners to become better at language learning. We free ourselves from the concept of learners possessing a fixed amount of aptitude for language, and see everyone capable of succeeding, given appropriate teaching. One of the challenges for the language teacher is to help learners to develop the strategies needed to learn a language more effectively, a principle which is embodied in the current work on learner training in English as a foreign language. It also follows that learning how to think effectively should be an important aspect of education. Learner training also involves teaching learners how to become more effective thinkers.

At the other extreme is the so-called constructivist movement, growing mainly out of the work of the developmental psychologist, Jean Piaget. Psychologists taking this approach have been mainly concerned with ways in which individuals come to make their own sense of the world. An important advocate of Piaget's ideas has been Jerome Bruner, Professor of Psychology and founder of the Centre for Cognitive Studies at Harvard University, particularly important for the implications of the discoveryapproach to language learning (Bruner 1960). To Bruner, the development of conceptual 
understanding and of cognitive skills and strategies is a central aim of education, rather than the acquisition of factual information.

One particularly significant aspect of Bruner's ideas is that they take a broad view of the education of the whole person. He saw as one of the central elements of this the need to learn how to learn, which he considered to be the key to transferring what was learned from one situation to another (1960:4). He argues that the first object of any act of learning is that it should serve us in the future. The limitation of such a view is that it does not represent the value of learning something for its own sake and neglects the relevance of any learning activity to the learner in the here and now.

One of Bruner's famous dictums is that the foundations of any subject may be taught to anybody at any age in some form. This gave rise to the notion of the spiral curriculum. The point here is that teachers should first introduce the basic ideas that give life and form to any topic and then revisit and build upon these repeatedly.

For Bruner the most general objective of education is the cultivation of excellence, which can only be achieved by challenging learners to exercise their full powers to become completely absorbed in problems and thereby discover the pleasure of full and effective functioning. Bruner claimed'that by encouraging young learners to discover for themselves the solutions to educational problems that were set for them in a way that was not artificially sectionalised into subjects, they could come to understand even the most complicated topics and relate their understanding in a meaningful way to a coherent knowledge of the world. He stresses also the importance of encouraging guesswork and intuitive thinking in learners. This will only occur if learners feel self-confident and able to take risks. Bruner's notion of purposefulness to help learners reach a coherent knowledge of the world has a message for us regarding the design of tasks for language learning. In Bruner's terms, "we need to seek a balance between, on the one hand teaching aspects of the target language and skills in the language, and on the other hand developing the learners' ability to analyse the language, to make guesses as to how rules operate, to take risks in trying out the language, and to learn from their errors".

An important stimulus for changing the way we teach language came during the 1970s when linguists and language educators began a reappraisal of language itself. Up to, and including 1960s, language was generally seen as a system of rules, and the task for language learners was to internalize these rules by whatever means were at their disposal. Language was seen as a unified system, and the ultimate aim of the learner was to approach the target language norms of the "native speaker". The priority for learners was to master the structures of the language, and, in this process, considerations of 
meaning were seen almost as peripheral. In fact, some language specialists argued that instruction should focus almost exclusively on teaching basic syntactic patterns, ignoring, or at least minimising, the development of vocabulary and semantic systems.

However, during the 1970s, a much richer conceptualisation of language began to emerge. Language was seen as a system for the expression of meaning, and linguists began to analize language as a system for the expression of meaning, rather than as a system of abstract syntactic rules.

The realisation that language could be analysed, described, and taught as a system for expressing meanings had a profound effect on language teaching.

The notion that it was not necessary for learners to master a particular grammatical structure or lexical item simply because it happened to be part of the system, coupled with the insight that what was learnt should reflect the different needs of different learner groups, was in harmony with the interpretative view of knowledge being fashioned within humanistic psychology and experiential learning.

\section{I.2 HUMANISM AND EXPERIENTIAL PSYCHOLOGY}

Out of the notion that learners are at the center of the learning process, and that learning is a process of self-discovery, grew experiential learning. In experiential learning, the learner's immediate personal experiences are taken as the point of departure for deciding how to organise the learning process.

Experiential learning has diverse origins, being derived by John Dewey's progressive philosophy of education, Lewin's social psychology, Piaget's model of developmental psychology, Kelley's cognitive theory of education, and the work of Abraham Maslow and Carl Rogers in the field of humanistic psychology. What draws these diverse philosophical and academic positions together is the construct of humanism.

Rogers (1969) identified a number of key elements of the humanistic approach to education. Beginning with the premise that human beings have a natural potential for learning, he suggested that significant learning will only take place when the subject matter is perceived to be of personal relevance to the learner and when it involves active participation by the learner, i.e. experiential learning. Learning which is self-initiated and which involves feelings as well as cognition is most likely to be lasting and pervasive. Independence, creativity and self-reliance are most likely to flourish in learning situations where external criticism is kept to a minimum and where self-evaluation is encouraged.

Humanistic approaches emphasize the importance of the inner world of the learner and place the individual's thoughts, feelings and emotions at the forefront of all human 
development. These are aspects of the learning process that are often neglected, yet they are vitally important if we are to understand human learning in its totality.

\section{I.3 IMPLICATIONS OF THE HUMANISTIC APPROACH}

Hamachek (1977) provides some useful examples of the kind of educational implications that follow from taking a humanistic approach:

First, every learning experience should be seen within the context of helping learners to develop a sense of personal identity and relating that to realistic future goals, i.e. learning should be personalised as far as possible.

Second, in order to realise one's full potential, learners should be helped and encouraged to make choices for themselves in what and how they learn.

Third, it is important for teachers to empathise with their learners by getting to know them as individuals and seeking to understand the ways in which they make sense of the world, rather than always seeking to impose their own viewpoints.

Thus, from a humanistic perspective, a learning experience of personal consequence occurs when the learner assumes the responsibility of evaluating the degree to which he or she is personally moving toward knowledge instead of looking to an external source for such evaluation.

\section{I.4 LEARNER-CENTERED EDUCATION}

Curriculum design in recent years has also been influenced by humanistic-affective currents of thought. Current researchers in the area of curriculum design have developed humanistic learner-centered models (Nunan 1988), which show the necessity of focusing more on language learners and their experience rather than simply on the narrower field of non-learner related linguistic corpora.

A learner-centered language curriculum takes affect into account in many ways. Participation in the decision-making process opens up greater possibilities for learners to develop their whole potential. In addition to the language content, they also learn responsibility, negotiation skills and self-evaluation, all of which lead to greater self.esteem and self-awareness. According to David Nunan (1988) learner-centered classrooms are those in which learners are actively involved in their own learning processes.

The philosophy of learner-centeredness has strong links with experiential learning, humanistic psychology and task-based language teaching.

A learner-centered curriculum will contain similar elements to those contained in traditional curriculum development, that is, planning, implementation and evaluation. 
However, the key difference between learner-centered and traditional curriculum development is that, in the former, the curriculum is a collaborative effort between teachers and learners, since learners are closely involved in the decision-making process regarding the content of the curriculum and how it is taught.

"One of the major assumptions underlying the learner-centered philosophy is that, given the constraints that exist in most learning contexts, it is impossible to teach learners everything they need to know in class. What little class time there is must therefore be used as effectively as possible to teach those aspects of the language which the learners themselves deem to be most urgently required, thus increasing surrender value and consequent student motivation." (Nunan, 1998: 3)

In consequence, while one major aim or set of aims will relate to the teaching of specific language skills, other aims will relate to the development of learning skills. Such aims may include the following:

- To provide learners with efficient learning strategies.

- To assist learners identify their own preferred ways of learning.

- To develop skills needed to negotiate the curriculum.

- To encourage learners to set their own objectives.

- To encourage learners to adopt realistic goals and time frames.

- To develop learners' skills in self-evaluation.

The term "learner-centered" often refers to classrooms in which learners are actively involved in the learning process. This kind of classroom is, in fact, consistent with a particular line of second language acquisition research that suggests acquisition is facilitated when opportunities for learners to interact are maximized.

\section{I.5 RESPONSIBILITY AND AUTONOMY}

This section is a brief overview of the ideas and problems connected to training learners for responsibility.

\section{I.5.I What makes a responsible learner?}

Responsible learners are those who accept the idea that their own efforts are crucial to progress in learning, and behave accordingly. So, when doing their homework or answering a question in class, they are not aspiring to please the teacher, or to get a good mark. They are simply making an effort in order to learn something.

Responsible learners do not have to be especially keen on team work, but they are 
willing to cooperate with the teacher and others in the learning group for everyone's benefit. Cooperation does not mean that they always obediently follow instructions: they may ask about the purpose of the activity first, or they may even come up with suggestions on how to improve an activity.

Finally, responsible students may not always do their homework, but whenever they fail to do it, they are aware of missing an opportunity to expand their knowledge of the foreign language. This is because they consciously monitor their own progress, and make an effort to use available opportunities to their benefit, including classroom activities and homework.

The last point leads to the question of defining autonomy.

\subsubsection{What makes an autonomous learner?}

In theory, we may define autonomy as the freedom and ability to manage one's own affairs, which entails the right to make decisions as well. Responsibility may also be understood as being in charge of something, but with the implication that one has to deal with the consequences of one's own actions. Autonomy and responsibility both require active involvement, and they are apparently very much interrelated.

In practice, the two concepts are more difficult to distinguish. Consider, for example, these three actions:

- Interrupting the teacher's explanation to ask about a certain point in the explanation.

- Looking up a word at home that the teacher used in the lesson but did not 'teach'.

- Paying special attention when the lesson is about something that the learner is not so good at.

In all these actions, learners behave responsibly as they are consciously making an effort to contribute to their learning. They are also autonomous in the sense that they act independently of the teacher, not waiting to be told what to do.

We may conclude that in order to foster learner autonomy, we clearly need to develop a sense of responsibility and also, encourage learners to take an active part in making decisions about their learning.

\subsubsection{Why should we develop responsibility and autonomy?}

The saying goes: you can bring the horse to water, but you cannot make him drink. In language learning, teachers can provide all the necessary circumstances and input, but learning can only happen if learners are willing to contribute. Their passive 
presence will not suffice, just as the horse would remain thirsty if he stood still by the river waiting patiently for his thirst to go away. And, in order for learners to be actively involved in the learning process, they first need to realize and accept that success in learning depends as much on the student as on the teacher. That is, they share responsibility for the outcome. In other words, success in learning very much depends on learners having a responsible attitude.

Some degree of autonomy is also essential to successful language learning. No matter how students learn through lessons, there is always plenty more they will need to learn by practice, on their own. Also, the changing needs of learners will require them to go back to learning several times in their lives: then again, they will need to be able to study on their own. The best way to prepare them for this task is to help them become more autonomous.

\section{I.6 WHAT CAN TEACHERS DO TO PROMOTE LEARNING?}

To provide learning experiences which are truly educational, the teacher can 'mediate' in a number of different ways. From the different features of mediation Feuerstein (1991) identifies, I will describe the most important ones in facilitating the learner's progression from one level to the next.

- Significance

The teacher should make learners aware of the significance of the learning task so that they can see the value of it.

- Purpose beyond the here and now

Leaners must be aware of the way in which the learning experience will have wider relevance to them beyond the immediate time and place.

- Control of own behaviour

The ability to control and regulate their own learning, thinking and actions.

- Goal-setting

The ability to set realistic goals and to plan ways of achieving them.

- Sharing

Co-operation among learners, together with the recognition that some problems are better solved co-operatively.

- Individuality

A recognition of their own individuality and uniqueness.

- Challenge

An internal need to respond to challenges, and to search for new challenges in life. 
In presenting learners with any learning task, teachers should convey to them precisely what they want them to do by providing a clear set of instructions. At the same time it is essential to ensure that learners understand exactly what is required of them, and that they are both able and willing to attempt it, so that they will approach the task in a self-directed way.

Since the ultimate purpose is to encourage autonomous learning, we should analyse other features of mediation that help learners to take control of their learning.

\subsubsection{A sense of competence}

Successful learners tend to be those who feel competent and capable of learning. In order to foster such feelings teachers should encourage a positive self-image, self-esteem, self-confidence, a feeling of 'I can'.

If learning is to be successful, it is crucial that teachers establish in their classrooms a climate where confidence is built up, where mistakes can be made without fear, where learners can use the language without embarrassment, where all contributions are valued, and where activities lead to feelings of success, not failure.

Feelings of competence are necessary; however, they are not sufficient for learning to be effective; learners need to become competent, that is, they need to learn the necessary skills and strategies in order to take control of their own learning.

\subsubsection{Control of behaviour}

It is important that teachers teach learners to take a logical and systematic approach to solving problems. This means learning how to break a problem down, to gather and assess information, to process the information, and to express results logically. In this way individuals can learn to take control of and responsibility for their own learning, so that they not only become more effective learners, but also independent ones.

In learning a foreign language, many learners do not feel that they are in control of their learning, that they can manage the process in a self-directed way. Thus we can see the importance of this aspect of mediation in language classrooms. It also provides us with theoretical support to the notion of learner training. Learner training means teaching learners how to learn languages, so that they are equipped with strategies to learn on their own, or to learn in class as effectively as possible. Teachers should develop activities that teach learners the strategies they need to learn a language, for example, analysing new pieces of language, processing input in order to work out rules, or ways of remembering new items of vocabulary. 


\section{FOCUS ON THE LEARNER}

Language teaching is often discussed from the point of view of the teacher. However, learners bring to learning their own beliefs, goals, attitudes, and decisions, which in turn influence how they approach their learning.

The language learner is the most important factor in the language learning process. Success or failure will, in the end, be determined by what learners themselves contribute. Learners draw upon their existing skills and knowledge and use their personal attributes in the process of learning. What we are concerned with here is how learners go about learning something; that is, the skills and strategies that they use and the processes that they go through in order to make sense of their learning.

\section{I LEARNER STRATEGIES}

Until recently the notion of learner strategies had been relatively neglected. In recent years, however, there has been great interest in the cognitive strategies people use to think, to learn and to solve problems. The impetus for this arose mainly from informationprocessing models of learning (cognitive psychology) and has given rise to research on these topics. What is clear from cognitive psychology is that learners are actively involved in making sense of the tasks or problems with which they are faced in order to learn. When confronted with a learning task, learners have various resources at their disposal and make use of them in different ways. Cognitive strategies are only one of the resources people have available to them but, we also make use of a variety of other processes to help us to learn something. We use our minds, but also our feelings and our social and communicative skills in active ways.

Over the last twenty years there has been a growing amount of research into language learning strategies (Rubin and Wenden 1987; O'Maley and Chamot 1990; Oxford 1990; Ellis and Sinclair 1999). This work is concerned with investigating how individuals go about the task of learning something and attempting to discover which of the strategies that learners use are the most effective for the particular type of learning involved.

\subsection{LEARNER TRAINING}

Learner training can be defined as a set of procedures or activities which raises learners' awareness to what is involved in learning a foreign language, which encourages learners to become more active, involved in and responsible for their own learning, and which helps them to develop and strengthen their strategies for language learning.

\section{8 / Cuadernos de lenguas Modernas}


Emphasis has been placed on training students to take charge of their own learning. According to Harmer (1991), the three main areas that are involved in this are:

\section{- PERSONAL ASSESSMENT \\ - LEARNING STRATEGIES \\ - laNGuAge AWARENESS}

\subsection{PERSONAL ASSESSMENT}

One of the aims of learner training is to make students think about what kind of learners they are and about what they can do to help themselves. A vital step in this process is getting students to think about their own learning behaviour, as in this example which has been taken from Ellis and Sinclair (1989):

Try the following quiz. Tick your answers to the questions.

\begin{tabular}{|l|l|l|l|l|}
\hline $\begin{array}{l}\text { I. Did/ do you get good results in } \\
\text { grammar tests? }\end{array}$ & usually & sometimes & Almost never & Don't know \\
\hline $\begin{array}{l}\text { 2. Do you have a good memory for new } \\
\text { words? }\end{array}$ & & & & \\
\hline 3. Do you hate making mistakes? & & & & \\
\hline $\begin{array}{l}\text { 4. In class, do you get irritated if mistakes } \\
\text { are not corrected? }\end{array}$ & & & & \\
\hline $\begin{array}{l}\text { 5. Is your pronunciation better when you } \\
\text { read aloud than when you have a } \\
\text { conversation? }\end{array}$ & & & & \\
\hline $\begin{array}{l}\text { 6. Do you wish you had more time to } \\
\text { think before speaking? }\end{array}$ & & & & \\
\hline $\begin{array}{l}\text { 7. Did/ do you enjoy being in class? } \\
\text { 8. Do you find it difficult to pick up more } \\
\text { language when you are on holiday abroad? }\end{array}$ & & & & \\
\hline $\begin{array}{l}\text { 9. Do you like to learn new grammar } \\
\text { rules, words, etc. by heart? }\end{array}$ & & & & \\
\hline
\end{tabular}


The students are now given a score for usually / never, etc, and based on their total score have their answers evaluated, e.g. 'Your score does not mean that you are not a good language learner. Perhaps this is the first time that you have thought about the way you learn...' (Ellis and Sinclair. 1989:8)

Other activities suggested by Ellis and Sinclair are keeping a personal motivation graph, talking about the best way of tackling reading or extending vocabulary knowledge.

The point of all these activities is to let students think hard about their learning and to use the insights they gain to help them to become more effective learners.

\subsubsection{LEARNING STRATEGIES}

If the teacher's job is to help students learn in a better way, then he or she will have to encourage students to develop learning strategies and autonomy. This will involve the students in personal assessment but it will also involve actually training students to behave in certain ways. This will include:

\section{Training students to use textbooks.}

Teachers can spend some time taking students through a new textbook, encouraging them to preview the book and find their way around it. The task below is intended for use at the beginning of a course. It could be undertaken in English with students from an intermediate level of language proficiency upwards, or in the first language with students at lower levels.

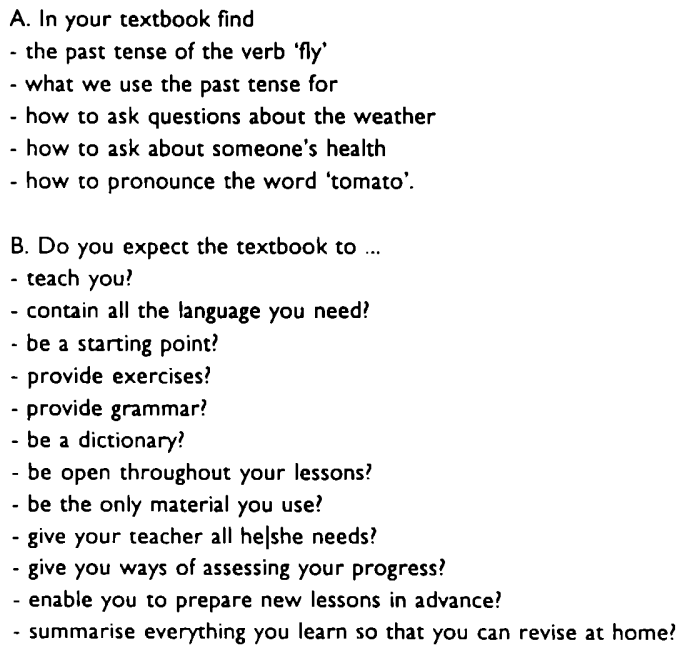

Teaching and Learning in the Language Classroom. Oxford University Press page 75 
The task addresses students' expectations of a textbook and asks them to reflect on its possible uses. The questions suggest implicitly that the textbook is only one source of learning and that it can be used independently by learners.

\section{Training students to use communicative activities properly.}

This involves the issue of mother tongue use. One of the biggest problems in the use of pairwork and groupwork is the use of the mother tongue by students in monolingual groups. It sometimes seems that they are unable or unwilling to take part in activities in English.

Teachers' attitude to the students' use of their own language should change depending on the activity they and we are involved in. If students are speaking in their own language rather than English during an oral communicative activity, then clearly the activity is fairly pointless. If, however, students are comparing their answers to reading comprehension questions, or trying to do a vocabulary matching exercise in pairs, then their occasional use of the mother tongue need not concern us. They are concentrating exclusively on English, and if a bit of their own language helps them to do this in a relaxed way, that is all to the good. It is important that students realise that our attitude to their language depends on the activity in question. If they do not know this, they will not know why and when we are insisting on 'English only'.

\section{Training students to read for gist.}

We must give students the ability to cope with texts outside the classroom and if we can help them to approach such texts confidently - then we will have done them a service.

\section{Training students to deal with unfamiliar vocabulary}

There are a number of discovery techniques from simple matching tasks to more complex understandings of connotation and contexts. For example:

- Matching words to pictures.

- Using the 'mind map' technique to help students to put a list of words into different groups.

- Guessing words through context.

\section{Training students to use dictionaries.}

When students look up a word in the dictionary, they have to deal with a variety of 
different information. We can get to this point by gradually training students to recognise symbols and conventions. For example, the teacher can ask the students to find out if a word they have encountered can be pluralised or not and ask them to find the information in their dictionaries. This is a way of training them to recognise the symbols for countable and uncountable nouns.

\subsubsection{LANGUAGE AWARENESS}

Teachers can design material that makes students more aware of the way in which language is used. One way of doing this is to make students do an exercise about language just as they do exercises about other topics like hobbies, films, adventure, etc. Frequently such activities can be done by the students studying on their own. The payoff is that as students complete the exercise they are being made more aware of how language works. The idea is simple: we can give students a text which is a story and we can ask them to look at it again to see how many ways they could find in it for referring to the past. By using these techniques, the teacher gets the students to do most of the work. There are good pedagogical and methodological reasons for this since the students will be more involved and since this kind of activity invites them to use their reasoning processes.

The following example will illustrate the idea. Here students are involved in studying the way in which the passive voice operates.

The following phrases/ sentences come from the newspaper articles on p.6I. Look at the verbs in each sentence and underline the active verb forms and circle the passive verb forms.

a ... a vet shot the tiger full of sedatives,...

b ... the injured man was carried to safety.

c... Flooding and landslides have killed up to 200 people ...

d....at least 70 people have been killed by floods and landslides ...

e ....a stolen car crashed into $8^{2}$ child's) bedroom.

$f$... Two teenagers were injured in the crash,...

$g$..., but they are expected to survive.

ANALYSIS

I. Look at sentence a) and b) above. In sentence a) the subject is 'a vet'; in sentence b) it is 'the injured man'? Is the subject the person who does the verb (the doer) in both sentences?

2. Below are two reasons why the passive is often used. Find another example of each use in the sentences above.

a. We use the passive when what happened to the person or thing is more important than 'the doer'?

Examples are sentence d) and sentence

b. We use the passive when the 'doer' of the verb is not known or not important.

Examples are sentence $b$ ) and sentence

Cutting Edge Intermediate, Longman page 62 
Learner training is vital if students are to achieve their full potential as learners. In its different forms it encourages them to think about their experiences, discuss them with the teacher and take action to make the whole process more effective.

\subsection{LEARNING STRATEGIES IN SECOND LANGUAGE ACQUISITION}

Second language teaching in recent years has moved away from the quest for the perfect teaching method, focusing instead on how successful teachers and learners actually achieve their goals. In the case of teachers, this has led to classroom-centered research on the linguistic, discoursal, and interactional structure of teaching events. In the case of learners, it has led to the study of (1) how learners approach learning, both in and out of classrooms, and (2) the kinds of strategies and cognitive processing they use in second language acquisition.

\subsection{LANGUAGE LEARNING STRATEGIES}

Following Wenden (1987) language learning strategies are the various operations that learners use in order to make sense of their learning. They refer to specific actions that a learner uses in response to a particular problem, rather than describing a learner's general approach to learning. They may be concerned with obtaining information, storage, retrieval or use of the information. Some strategies are observable and some are not. They may be used consciously or unconsciously and they can be learned. Strategies can be cognitive (i.e. they can involve mental processing), or they can be more social in nature, and their effective use is enhanced by metacognitive awareness.

\subsection{COGNITIVE AND METACOGNITIVE STRATEGIES}

O'Maley and Chamot (1990), Oxford (1990), Wenden (199I) have classified strategies into cognitive and metacognitive strategies. Cognitive strategies are seen as mental processes directly concerned with the processing of information in order to learn, that is for obtaining, storage, retrieval or use of information. However, there is another set of strategies operating at a different level to these, which involve learners stepping outside their learning and looking at it from outside. Such strategies include an awareness of what one is doing and the strategies one is employing, as well as knowledge about the actual process of learning. They also include an ability to manage and regulate consciously the use of appropriate learning strategies for different situations. They involve an awareness of one's own mental processes and an ability to reflect on how one learns. This different level is called metacognition. Metacognitive awareness is important for 
effective learning.

\section{RESEARCH ON LEARNING STRATEGIES}

Research into language learning strategies began in the 1960s. Much of this has been influenced by developments in cognitive psychology.

The literature on learning strategies in second language acquisition emerged from a concern for identifying the characteristics of effective learners. In 1975 Rubin investigated what 'good language learners' did to facilitate their learning. According to Rubin, good language learners are willing and accurate guessers who have a strong desire to communicate, and will attempt to do so even at the risk of appearing foolish. They attend to both the meaning and the form of their message. They also practice and monitor their own speech as well as the speech of others.

Learner strategy research has focused on studying how learners use strategies and what the differences are between the strategies used by successful and unsuccessful learners. Through observing learners as they complete different language learning tasks and through having them introspect about strategies or writing about how they solve particular language learning problems, differences between effective and ineffective strategies can be identified.

Nunan (1999) found that one of the characteristics of the "good" language learner was an ability to reflect on and articulate the processes underlying their own learning. Similarly, in an overview of research into strategy training, O'Malley and Chamot (1990) found indications that more effective learners use strategies more frequently and use a greater variety of strategies than students who were designated as less effective.

In their well-known study of 'the good language learner', Rubin and Thompson (1994) suggest that good or efficient learners tend to exhibit specific characteristics as they go about learning a second language. These characteristics are the following:

\section{- CHARACTERISTICS OF THE GOOD LANGUAGE LEARNER}

According to Rubin and Thompson (1994) GOOD LEARNERS:

- find their own way.

- organize information about language.

- are creative and experiment with language. 
- make their own opportunities, and find strategies for getting practice in using the language inside and outside the classroom.

- learn to live uncertainty and develop strategies for making sense of the target language without wanting to understand every word.

- use mnemonics (rhymes, word associations, and so forth) to recall what has been learned.

- make errors work.

- use linguistic knowledge, including knowledge of their first language in mastering a second language.

- let the context (extralinguistic knowledge and knowledge of the world) help them in comprehension.

- learn to make intelligent guesses.

- learn chunks of language as wholes and formalized routines to help them perform 'beyond their competence'.

- learn production techniques (e.g. techniques for keeping conversation going).

- learn different styles of speech and writing and learn to vary their language according to the formality of the situation.

Research efforts concentrating on the good language learner had identified strategies reported by students or observed in language learning situations that appear to contribute to learning. These efforts demonstrated that students do apply learning strategies while learning a second language and that these strategies can be described and classified. However, the diverse range of learners and the different learning settings (naturalistic or classroom) used by the researchers in their studies have resulted in the use of varied and sometimes overlapping terminology.

Rubin (1975) defines strategies as: 'techniques or devices which a learner may use to acquire knowledge' (p.43) and proposed a classification scheme that subsumes learning strategies under two primary groupings and a number of subgroups, as illustrated in Table I.I below.

Rubin suggests that there are three major types of strategies used by learners which can contribute directly or indirectly to language learning. The first primary group she calls learning strategies. These contribute directly to the development of the language system which the learner constructs. They include both cognitive and metacognitive strategies. She identifies six main strategies contributing directly to language learning. They include clarification/verification, monitoring, memorisation, guessing/inductive 
reasoning, deductive reasoning, and practice. Metacognitive strategies, in Rubin's categorization, are used to oversee, regulate or self-direct language learning. They involve such processes as planning, prioritising, setting goals and self-management.

The second primary category, consisting of strategies that contribute indirectly to learning, includes creating practice opportunities and using production tricks such as communication strategies. They are strategies used by learners to promote communication with others, or when they come across a difficulty in their communication because of a lack of adequate knowledge of the language. These processes are particularly important to language learners, as by finding ways to continue the communication rather than abandon it, the speaker indirectly obtains more exposure to the language and an opportunity to practise it.

\begin{tabular}{|c|c|c|}
\hline $\begin{array}{l}\text { Primary strategy } \\
\text { classification }\end{array}$ & $\begin{array}{l}\text { Representative } \\
\text { secondary strategies }\end{array}$ & $\begin{array}{l}\text { Representative examples } \\
\text { The learner... }\end{array}$ \\
\hline \multirow[t]{5}{*}{$\begin{array}{l}\text { Strategies that directly } \\
\text { affect learning }\end{array}$} & Clarification/verification & $\begin{array}{l}\text { asks for an example of how to use a word or } \\
\text { expression, repeats words to confirm } \\
\text { understanding }\end{array}$ \\
\hline & Monitoring & $\begin{array}{l}\text { corrects errors in own/ other's pronunciation, } \\
\text { vocabulary, spelling, grammar, style }\end{array}$ \\
\hline & Memorization & $\begin{array}{l}\text { takes note of new items, pronounces out loud, } \\
\text { finds a mnemonic, writes items repeatedly }\end{array}$ \\
\hline & $\begin{array}{l}\text { Guessing/ inductive } \\
\text { inferencing }\end{array}$ & $\begin{array}{l}\text { guesses meaning from key words, structures, } \\
\text { pictures, context, etc. }\end{array}$ \\
\hline & Deductive reasoning & $\begin{array}{l}\text { compares native/ other language to target language } \\
\text { Groups words } \\
\text { Looks for rules of co-occurence }\end{array}$ \\
\hline \multirow[t]{3}{*}{$\begin{array}{l}\text { Processes that contribute } \\
\text { indirectly to learning }\end{array}$} & Practice & $\begin{array}{l}\text { experiments with new sounds } \\
\text { Repeats sentences until pronounced easily } \\
\text { Listens carefully and tries to imitate }\end{array}$ \\
\hline & $\begin{array}{l}\text { Creates opportunities for } \\
\text { practice }\end{array}$ & $\begin{array}{l}\text { creates situation with native speaker } \\
\text { Initiates conversation with fellow students } \\
\text { Spends time in language lab, listening to TV, etc }\end{array}$ \\
\hline & Production tricks & $\begin{array}{l}\text { uses circumlocutions, synonyms, or cognates } \\
\text { Uses formulaic interaction } \\
\text { Contextualizes to clarify meaning }\end{array}$ \\
\hline
\end{tabular}

Table I.I Rubin's (1975) classification of learning strategies 
In cognitive psychology, studies of learning strategies with first language learners have concentrated on determining the effects of strategy training on different kinds of tasks and learners. Findings from these studies generally indicated that strategy training is effective in improving the performance of students on a wide range of reading comprehension and problem solving tasks.

Following O'Maley and Chamot's (1990) classification and definition of strategies, metacognitive strategies involve thinking about the learning process, planning for learning, monitoring of comprehension or production while it is taking place, and self-evaluation after the learning activity has been completed, while cognitive strategies are more directly related to individual learning tasks and entail direct manipulation or transformation of the learning materials. A third type of learning strategy identified in the literature on cognitive psychology concerns the influence of social and affective processes on learning. Examples of social/ affective strategies are cooperative learning, which involves peer interaction to achieve a common goal in learning, and asking questions for clarification. Affective strategies are represented in the exercise of "self-talk", the redirecting of negative thoughts about one's capability to perform a task with assurances that the task performance is within reach.

Research in metacognitive and cognitive learning strategies suggests that transfer of strategy training to new tasks can be maximized by pairing metacognitive strategies with appropriate cognitive strategies. Students without metacognitive approaches are essentially learners without direction or opportunity to plan their learning, monitor their progress, or review their accomplishments and future learning direction.

More recent work on learning strategies in second language acquisition has been more focused. Wenden (1987) concentrated on self-directed learning among adult foreign language learners. Wenden explored self-directed language learning activities in a variety of social settings and concluded that the self-directed activities could be characterised by eight questions learners might pose to themselves that lead to decisions about language learning practices. The chart below lists the questions and the corresponding decisions within three designators - knowing about learning, planning and self-evaluation. 


\begin{tabular}{|l|l|}
\hline Knowing about learning & \\
\hline Question: How does this language work? & $\begin{array}{l}\text { Decision: Learners make judgements about the linguistic } \\
\text { and sociolinguistic codes. }\end{array}$ \\
\hline Question: What's it like to learn a language? & $\begin{array}{l}\text { Decision: Learners make judgements about how to learn a } \\
\text { language and about what language learning is like. }\end{array}$ \\
\hline Planning & $\begin{array}{l}\text { Decision: Learners decide on linguistic objectives, } \\
\text { resources, and use of resources. }\end{array}$ \\
\hline Question:What should I learn and how? & $\begin{array}{l}\text { Decision: Learners decide to give priority to special } \\
\text { linguistic items. }\end{array}$ \\
\hline Question:What should I emphasize? & $\begin{array}{l}\text { Decision: Learners decide to change their approach to } \\
\text { language learning. }\end{array}$ \\
\hline Question: How should I change? & $\begin{array}{l}\text { Decision: Learners determine if an activity or strategy is } \\
\text { useful. }\end{array}$ \\
\hline Selfevaluation & $\begin{array}{l}\text { Decision: Learners make judgements about how to learn a } \\
\text { language and about what language learning is like. }\end{array}$ \\
\hline Question: How am I doing? & language and diagnose their needs. \\
\hline Question: What am I getting? & learning affecting me?
\end{tabular}

\section{Table I.2 Wenden's characterisation of self-directed activities}

The definition and categorisation of language learning strategies was further developed by Rebecca Oxford (1990) in her book Language Learning Strategies: What every teacher should know. Oxford sees the aim of language learning strategies as being oriented towards the development of communicative competence, and that they must, therefore, involve interaction among learners. Learning strategies must both help learners to participate in communication and to build up their language system. Oxford provides a list of twelve features of language learning strategies.

I. They contribute to the main goal, communicative competence. They can foster particular aspects of that competence: grammatical competence, sociolinguistic competence, discourse competence, and strategic competence. 
2. They allow learners to become more self-directed. The aim of teaching learning strategies is to help learners to take control of their own learning.

3. They expand the role of teachers. New teaching capacities also include identifying students' learning strategies, conducting training on learning strategies and helping learners to become more independent.

4. They are problem-oriented. They are used in response to a particular problem.

5. They are specific actions taken by the learner. They are specific behaviour in response to a problem.

6. They involve many actions taken by the learner, not just the cognitive. They involve affective and social aspects as well.

7. They support learning both directly and indirectly. I shall discuss this point further below.

8. They are not always observable. Many aspects of cooperating, a strategy in which the learner works with someone else to achieve a learning goal, can be observed, but the act of making mental associations, an important memory strategy, cannot be seen.

9. They are often conscious. Strategy training helps learners to become more aware of the strategies they use, and to distinguish between appropriate and inappropriate ones. However, the aim must be to enable learners to use appropriate strategies automatically and unconsciously.

10. They can be taught. People can improve their learning through strategy training. II. They are flexible. Learner exert choice over the way they use, combine and sequence strategies.

12. They are influenced by a variety of factors. For example, stage of learning, task requirements, age, sex, nationality, general learning style, motivation and purpose for learning the language.

Oxford (1990) has also developed a system of categorisation which, while containing most of the features of previous classifications, is more detailed. She divides strategies into two main classes, direct and indirect, which are further subdivided into six groups.

In Oxford's system, direct strategies include: (a) memory strategies, which are those used for storage of information, (b) cognitive strategies, which are the mental strategies learners use to make sense of their learning and (c) compensation strategies, which help learners to overcome knowledge gaps and to continue the communication.

Indirect strategies are classified into: (a) metacognitive strategies, which help learn- 
ers to regulate their learning, (b) affective strategies, which are concerned with the learner's emotional requirements and (c) social strategies, which lead to increased interaction with the target language.

\begin{tabular}{|c|c|c|}
\hline \multicolumn{3}{|c|}{ DIRECT STRATAGIES } \\
\hline \multirow{4}{*}{$\begin{array}{l}\text { Memory } \\
\text { Which help students } \\
\text { to store and retrieve } \\
\text { information }\end{array}$} & $\begin{array}{l}\text { Creating mental } \\
\text { linkages }\end{array}$ & $\begin{array}{l}\text { - Grouping } \\
\text { - Associating/elaborating } \\
\text { - Placing new words into a context }\end{array}$ \\
\hline & $\begin{array}{l}\text { Applying images and } \\
\text { sounds }\end{array}$ & $\begin{array}{l}\text { - Using imagery } \\
\text { - Semantic mapping } \\
\text { - Using keywords } \\
\text { - Representing sounds in memory }\end{array}$ \\
\hline & Reviewing well & - Structured reviewing \\
\hline & Employing action & $\begin{array}{l}\text { - Using physical response or sensation } \\
\text { - Using mechanical techniques }\end{array}$ \\
\hline \multirow{4}{*}{$\begin{array}{l}\text { Cognitive } \\
\text { Which enable } \\
\text { learners to } \\
\text { understand and } \\
\text { produce new } \\
\text { language }\end{array}$} & Practicing & $\begin{array}{l}\text { - Repeating } \\
\text { - Formally practicing with sounds and writing systems } \\
\text { - Recognizing and using formulas and patterns } \\
\text { - Recombining } \\
\text { - Practicing naturalistically }\end{array}$ \\
\hline & $\begin{array}{l}\text { Receiving and sending } \\
\text { messages }\end{array}$ & $\begin{array}{l}\text { - Getting the idea quickly } \\
\text { - Using resources for receiving and sending mes- } \\
\text { sages }\end{array}$ \\
\hline & Analyzing and reasoning & $\begin{array}{l}\text { - Reasoning deductively } \\
\text { - Analysing expressions } \\
\text { - Analysing contrastively } \\
\text { - Translating } \\
\text { - Transferring }\end{array}$ \\
\hline & $\begin{array}{l}\text { Creating structure for } \\
\text { input and output }\end{array}$ & $\begin{array}{l}\text { - Taking notes } \\
\text { - Summarizing } \\
\text { - Highlighting }\end{array}$ \\
\hline \multirow{2}{*}{$\begin{array}{l}\text { Compensation } \\
\text { Which allow } \\
\text { learners to } \\
\text { comunicate despite } \\
\text { deficiencies in } \\
\text { language knowledge }\end{array}$} & Guessing intelligently & $\begin{array}{l}\text { - Using linguistic clues to guess meaning } \\
\text { - Using other clues }\end{array}$ \\
\hline & $\begin{array}{l}\text { Overcoming limitations } \\
\text { in speaking and writing }\end{array}$ & $\begin{array}{l}\text { - Switching to the mother tongue } \\
\text { - Getting help } \\
\text { - Using mime or gesture } \\
\text { - Avoiding communication partially or totally } \\
\text { - Selecting the topic } \\
\text { - Adjusting or approximating the message } \\
\text { - Coining words } \\
\text { - Using a circumlocution or synonym }\end{array}$ \\
\hline
\end{tabular}

Table 1.3 Oxford's (1990) classification of direct learning strategies. 


\begin{tabular}{|c|c|c|}
\hline \multicolumn{3}{|c|}{ INDIRECT STRATAGIES } \\
\hline \multirow[t]{3}{*}{$\begin{array}{l}\text { Metacognitive } \\
\text { Which allow learners to } \\
\text { control their own learning } \\
\text { through organizing, planning } \\
\text { and evaluating }\end{array}$} & $\begin{array}{l}\text { Centering your } \\
\text { learning }\end{array}$ & $\begin{array}{l}\text { - Overviewing and linking new information } \\
\text { with already known material } \\
\text { - Paying attention } \\
\text { - Delaying speech production to focus on } \\
\text { listening }\end{array}$ \\
\hline & $\begin{array}{l}\text { Arranging and planning } \\
\text { your learning }\end{array}$ & $\begin{array}{l}\text { - Finding out about language learning } \\
\text { - Organizing } \\
\text { - Setting goals and objectives } \\
\text { - Identifying the purpose of a language task } \\
\text { - Planning for a language task } \\
\text { - Seeking practice opportunities }\end{array}$ \\
\hline & $\begin{array}{l}\text { Evaluating your learn- } \\
\text { ing }\end{array}$ & $\begin{array}{l}\text { - Self-monitoring } \\
\text { - Self-evaluating }\end{array}$ \\
\hline \multirow[t]{3}{*}{$\begin{array}{l}\text { Affective } \\
\text { Which help students gain } \\
\text { control over their emotions, } \\
\text { actitudes, motivations and } \\
\text { values }\end{array}$} & Lowering your anxiety & $\begin{array}{l}\text { - Using progressive relaxation, deep breathing, } \\
\text { or meditation } \\
\text { - Using music } \\
\text { - Using laughter }\end{array}$ \\
\hline & Encouraging yourself & $\begin{array}{l}\text { - Making positive statements } \\
\text { - Taking risks wisely } \\
\text { - Rewarding yourself }\end{array}$ \\
\hline & $\begin{array}{l}\text { Taking your emotional } \\
\text { temperature }\end{array}$ & $\begin{array}{l}\text { - Listening to your body } \\
\text { - Using a checklist } \\
\text { - Writing a language learning diary } \\
\text { - Discussing your feelings with someone else }\end{array}$ \\
\hline \multirow{3}{*}{$\begin{array}{l}\text { Social } \\
\text { Which help learners interact } \\
\text { with other people }\end{array}$} & Asking questions & $\begin{array}{l}\text { - Asking for clarification or verification } \\
\text { - Asking for correction }\end{array}$ \\
\hline & $\begin{array}{l}\text { Cooperating with oth- } \\
\text { ers }\end{array}$ & $\begin{array}{l}\text { - Cooperating with peers } \\
\text { - Cooperating with proficient users of the new } \\
\text { language }\end{array}$ \\
\hline & $\begin{array}{l}\text { Empathising with oth- } \\
\text { ers }\end{array}$ & $\begin{array}{l}\text { - Developing cultural understanding } \\
\text { - Becoming aware of others'thoughts and } \\
\text { feelings }\end{array}$ \\
\hline
\end{tabular}

Table 1.4 Oxford's (1990) classification of indirect learning strategies.

What Oxford did was to subsume within her classification every strategy that had previously been cited in the literature on learning strategies. The problem with this approach is that this extended listing fails to prioritise which strategies are most important 
to learning, and generates subcategories that appear to overlap.

It can be seen that much of the recent work in this area has been underpinned by a broader concept of language learning strategies that goes beyond cognitive processes to include social and communicative strategies. A point worth emphasising here is the link between the emotions and cognition. Our feelings will affect our use of cognitive processes and viceversa.

\section{I THE THEORY OF LEARNER TRAINING}

\section{I.I THE AIMS OF LEARNER TRAINING}

Learner training aims to help learners consider the factors that affect their learning and discover the learning strategies that suit them best so that they may:

- become more effective learners.

- take on more responsibility for their own learning.

It focuses students' attention on the process of learning so that the emphasis is on how to learn rather than on what to learn.

Learner training is based on the following assumptions:

- that individuals learn in different ways and may use a variety of learning strategies at different times depending on a range of variables, such as the nature of the learning task, mood, motivation levels;

- that the more informed learners are about language and language learning the more effective they will be at managing their own learning.

Helping learners take on more responsibility for their own learning can be beneficial for the following reasons:

learning can be more effective when learners take control of their own learning because they learn what they are ready to learn;

those learners who are responsible for their own learning can carry on learning outside the classroom;

learners who know about learning can transfer learning strategies to other subjects.

Learner training, therefore, aims to provide learners with the alternatives from which to make informed choices about what, how, why, when and where they learn. In order 
to be able to make such choices about their learning, it follows that the learners need to be informed about the language itself (through language awareness activities), about language learning techniques and processes (through experimentation and reflection) and about themselves as language learners (through regular self-assessment and introspection).

As learners become more informed, they are more likely to be more effective and better motivated as learners.

Learner training is, then, related to the concept of learner autonomy in that it aims to provide learners with the ability to take on more responsibility for their own learning. Its aim is to prepare learners for independence.

Learner training espouses the belief that everybody has the right to develop the capacity for taking charge of his or her own affairs and that this development is a basic function of education.

Many teachers have felt the need to expand their role by including, for example, language awareness activities, study skills, opportunities for learner choice and by helping learners learn how to learn. The procedures and techniques for doing this have become known as learner training.

\section{PART II}

\section{WHAT ARE LEARNING STRATEGIES?}

\section{I.I Defining strategies}

1.2 The importance of strategies to the learning process

1.3 Direct and indirect strategies

\section{LEARNING STRATEGIES AND TASKS}

2.1 A typology of learning strategies

\section{INTRODUCING STRATEGIES IN THE CLASSROOM}

3.I Sample classroom tasks

\section{ENCOURAGING LEARNER INDEPENDENCE}

\section{I Goal setting}

4.2 Self-assessment and evaluation

4.3 Learner choice 
4.4 Causes of learner failure

4.5 A sample lesson

5. STRATEGIES GROUPED ACCORDING TO THE FOUR LANGUAGE SKILLS

5.I Learner training and study skills

5.2 Towards improving the students' reading comprehension

5.3 Reading strategies

5.4 Writing strategies

5.5 Listening strategies

5.6 Strategies in speaking English

\section{STRATEGIES FOR LEARNING VOCABULARY}

\section{CONCLUSION}

\section{WATH ARE LEARNING STRATEGIES?}

It is important to clarify what we mean by a learning strategy. Most of us have probably used some or all of the following in learning a foreign language:

repeating words over and over again

- listening attentively to try to distinguish words

trying to work out the rules of the language by forming hypothesis about how it works

trying out these hypothesis to see if they work

- testing yourself to see if you remember words

- guessing the meanings of unknown words

- using your knowledge of language rules to try to make new sentences

- rehearsing in your head what you are about to say

- practising the sounds of the language

- asking a speaker to repeat something

- pretending that you understand in order to keep the communication going

These are some of the many strategies that people use to try to succeed in the complex task of learning a language. 


\section{I.I DEFINING STRATEGIES}

Strategies are the mental and communicative procedures learners use in order to learn and use language. Underlying every learning task is at least one strategy. However, in most classrooms, learners are unaware of the strategies underlying the learning tasks in which they are engaged. When confronted with a classroom learning task, such as reading a chapter of a book or preparing a written summary of a passage, the learner can choose several different ways of completing the task. Each of these choices or strategies offers particular advantages or disadvantages, and the use of an appropriate learning strategy can enhance success in the learning task. An important aspect of teaching is to promote learners' awareness and control of effective learning strategies and discourage the use of ineffective ones.

\section{I.2 THE IMPORTANCE OF STRATEGIES TO THE LEARNING PROCESS}

Rebecca Oxford (1990) argues that strategies are important for two reasons. In the first place, strategies "are tools for active, self-directed involvement, which is essential for developing communicative competence" (1990: 1). Secondly, learners who have developed appropriate learning strategies have greater self-confidence and learn more effectively.

\subsection{DIRECT AND INDIRECT STRATEGIES}

Oxford draws a distinction between direct and indirect strategies.

Language learning strategies that directly involve the target language are called direct strategies. All direct strategies require mental processing of the language. Indirect strategies, on the other hand, support and manage language learning without directly involving the target language. Direct and indirect strategies are equally important and serve to support each other in many ways.

\section{LEARNING STRATEGIES AND TASKS}

\section{I A TYPOLOGY OF LEARNING STRATEGIES}

Underlying every task that the teacher introduces into the classroom is a learning strategy of one kind or another.

Nunan (1999) developed the following typology of strategies. Some of these strategies will be used more often than others depending on the age and proficiency of the 
students, the skills being focused on, and the individual learner needs. In the rest of this section, I mention some of the more commonly used learning strategies and I illustrate each strategy by means of one or more activities extracted from recently published textbooks. It is worth mentioning that an increasing number of authors have become aware of the importance of learning strategy training and have started to build this into their materials.

\begin{tabular}{|c|c|}
\hline COGNITIVE & \\
\hline Classifying & $\begin{array}{l}\text { Putting things that are similar together in groups. } \\
\text { Example. Study a list of names and classify them into male and female. }\end{array}$ \\
\hline Predicting & $\begin{array}{l}\text { Predicting what is to come in the learning process. } \\
\text { Example. Look at unit title and objectives and predict what will be learnt. }\end{array}$ \\
\hline Inducing & $\begin{array}{l}\text { Looking for patterns and regularities. } \\
\text { Example. Study a conversation and discover the rule for forming the } \\
\text { simple past tense. }\end{array}$ \\
\hline Taking notes & Writing down the important information in a text in you own words. \\
\hline Concept Mapping & Showing the main ideas in a text in the form of a map. \\
\hline Inferencing & Using what you know to learn something new. \\
\hline Discriminating & Distinguishing between the main idea and supporting information. \\
\hline Diagramming & Using information from a text to label a diagram. \\
\hline \multicolumn{2}{|l|}{ INTERPERSONAL } \\
\hline Cooperating & $\begin{array}{l}\text { Sharing ideas and learning with other students. } \\
\text { Example. Work in small groups to read a text and complete a table. }\end{array}$ \\
\hline Role-playing & $\begin{array}{l}\text { Pretending to be somebody else and using the language for the situation } \\
\text { you are in. } \\
\text { Example. You are a reporter. Use the information from the reading to } \\
\text { interview the writer. }\end{array}$ \\
\hline
\end{tabular}




\begin{tabular}{|c|c|}
\hline LINGUISTIC & \\
\hline Conversational Patterns & $\begin{array}{l}\text { Using expressions to start conversations and keep them going. } \\
\text { Example: Match formulaic expressions to situations. }\end{array}$ \\
\hline Practising & $\begin{array}{l}\text { Doing controlled exercises to improve knowledge and skills. } \\
\text { Exercise: Listen to a conversation and practice it with a partner. }\end{array}$ \\
\hline Using context & $\begin{array}{l}\text { Using the surrounding context to guess the meaning of unknown } \\
\text { words, phrases, and concepts. }\end{array}$ \\
\hline Summarizing & Picking out and presenting the major points in a text in summary form. \\
\hline Selective Listening & $\begin{array}{l}\text { Listening for key information without trying to understand every } \\
\text { word. } \\
\text { Example: Listen to a conversation and identify the number of speak- } \\
\text { ers. }\end{array}$ \\
\hline Skimming & $\begin{array}{l}\text { Reading quickly to get a general idea of a text. } \\
\text { Example: Decide if a text is a newspaper article, a letter, or an adver- } \\
\text { tisement. }\end{array}$ \\
\hline Scanning & $\begin{array}{l}\text { Reading quickly to find specific information. } \\
\text { Example: For one minute scan the article looking specifically for the } \\
\text { reasons why the writer quit the company. }\end{array}$ \\
\hline \multicolumn{2}{|l|}{ CREATIVE } \\
\hline Brainstorming & $\begin{array}{l}\text { Thinking of as many new words and ideas as you can. } \\
\text { Example: Work in a group and think of as many occupations as you } \\
\text { can }\end{array}$ \\
\hline \multicolumn{2}{|l|}{ AFFECTIVE } \\
\hline Personalising & $\begin{array}{l}\text { Learners share their own opinions, feelings, and ideas about a subject. } \\
\text { Example: Read a letter from a friend in need and give advice. }\end{array}$ \\
\hline Reflecting & Thinking about ways you learn best. \\
\hline $\begin{array}{l}\text { Setting Goals And Objec- } \\
\text { tives }\end{array}$ & $\begin{array}{l}\text { Setting aims for language learning, including long-term goals or short- } \\
\text { term objectives. }\end{array}$ \\
\hline Self-Evaluating & $\begin{array}{l}\text { Thinking about how well you did on a learning task, and rating yourself } \\
\text { on a scale. }\end{array}$ \\
\hline
\end{tabular}




\section{INTRODUCING STRATEGIES IN THE CLASSROOM}

\section{I SAMPLE CLASSROOM TASKS}

\section{I.I COGNITIVE STRATAGIES}

\section{- CLASSIFYING}

Tasks such as the following that require learners to put vocabulary items into their semantic groups are classification tasks. Classifying helps learners because it is easier to memorise items that are grouped together in meaningful ways than trying to remember isolated items.

Put these adjectives in the correct category

\begin{tabular}{|l|l|l|l|l|l|l|l|c|}
\hline attractive & big & black & cloth & cotton & curved & English & fashionable & glass \\
\hline gold & hard & heavy & Italian & large & leather & light & metal & oval \\
\hline round & red & small & soft & square & wood & woolen & rectangular & white \\
\hline
\end{tabular}

\begin{tabular}{|c|c|c|c|c|c|}
\hline Opinion & Size/weightTexture & Shape & Colour & Origin & Material \\
\hline & & & & & \\
\hline & & & & & \\
\hline & & & & & \\
\hline & & & & & \\
\hline & & & & & \\
\hline
\end{tabular}

Flying Colours 2. Workbook, Heinemann (page 40)

PREDICTING

Predicting, or looking ahead, helps learners to anticipate what is to come. This results in more effective learning, because the learners are adequately prepared for the new material. 
I.Look at this photo of a boy and girl meeting for the first time on a beach in Portugal.

What do you think they might talk to one another about? Talk to the rest of the class.

Agree on at least six points and write them below.

a)-

b)

c)

d)

e)

f)

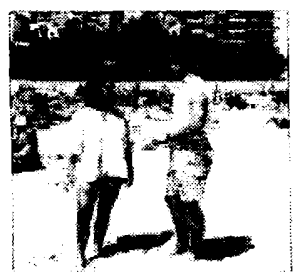

2. Now listen to the tape. Do the boy and girl talk about the points you listed above? Write yes

(V) or no $(\mathrm{N})$ against each point.

Tuning In, Longman (page 10)

\section{INDUCTIVE REASONING}

In an inductive approach to learning, students are given access to data, and are provided with structured opportunities to work out rules, principles, and so on for themselves. The idea here is that information will be more deeply processed and stored if learners are given an opportunity to work things out for themselves, rather than simply being told.

\section{ANALYSIS}

I. Which sentence below refers to:

a) a real possibility in the future?

b) an imaginary situation?

- I'd never lend a friend a lot of money.

- I'll never lend her any money again.

Which verb form is used in each case?

Find two more examples with would in Exercise 2 above.

2. We often talk about hypothetical situations using if. Find three examples of this in Exercise 2 above. Which tense is used after if? Does it refer to a past time?

I. Sometimes (but not always) the hypothetical forms in questions $I$ and 2 are used together. Which one of the sentences below is incorrect?

- If he or she really needed it, l'd lend a large amount of money to a friend.

- If my friend would need it, I would lend a large amount of money to him or her.

- I might lend a large amount of money to a friend if he or she really needed it.

What is the difference between the two correct sentences?. Now read Language summary B on pages /47-148.

Cutting Edge Intermediate, Longman (page 94) 


\section{TAKING NOTES}

This is a very important strategy for listening and reading. The focus of taking notes should be on understanding, not writing. Taking notes as you read or listen helps you organize and remember important information. Note-taking is often thought of as an advanced tool, to be used at high levels of proficiency- such as when listening to lectures. However, developing note-taking strategies can begin at very early stages of learning.

Use your margin notes and the ideas that you underlined in the article to complete the chart below. Be sure to use your own words.

\begin{tabular}{|c|c|c|}
\hline PARAGRAPH & TOPIC & SUMMARY OF INFORMATION \\
\hline $\begin{array}{l}1 \\
2 \\
3 \\
4 \\
5 \\
6\end{array}$ & author's occupation & $\begin{array}{l}\text { The author teaches people about body } \\
\text { language in her university classes and in } \\
\text { training seminars. }\end{array}$ \\
\hline
\end{tabular}

Compare charts with your classmates

Multicultural Workshop-Book 3 ,Heinle\& Heinle (page 64)

- CONCEPT MAPPING

Making an arrangement of words into a picture, which has groups of words linked with the key concept by means of lines or arrows. This strategy involves meaningful imagery, grouping, and associations; it visually shows how certain groups of words relate to each other.

Add words to the word map.

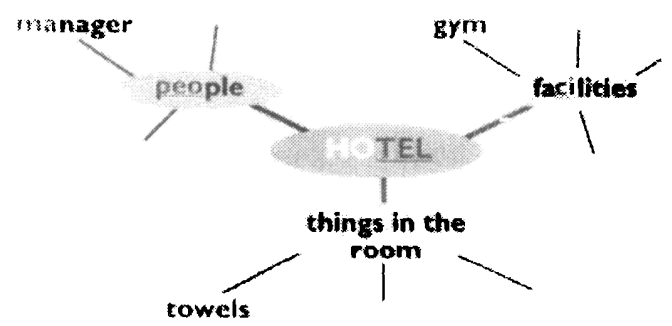

English File 2, OUP. (Page 50) 


\section{INFERENCING}

Inferencing involves using what you know to learn something new. Because learning is basically making links between what is new and what is already known, inferencing is an extremely important strategy.

PAIR WORK. What inferences can you make about the characters in the story based on the lines below?

a. "Unlike my other math teachers..., he (Mir. Antonelli) didn't seem to find it bizarre that a girl should do well in his class. As for my being Chinese, I doubt if he even noticed."

What can you infer about Mr. Antonelli?

b. "I have only the vaguest memories of my other classes that afternoon. I bareiy realized when the final bell rang. Leaving school, I almost hugged my books to my chest. It was like waking up on my birthday and finding a pile of presents outside my door."

What can you infer about the narrator? How does she feel?

Compare ideas with your classmates.

Multicultura/ Workshop-Book 3, Heinle\& Heinle. (Page 8I)

- DISCRIMINATING

Discriminating means distinguishing between the main idea and supporting information in both aural and written texts. Learners who are skilled at identifying the most important information in a text are more effective listeners and readers. They can process language more quickly, and are able to identify and remember the speaker or reader's central message more effectively.

The topic or subject of the reading on pages $98-99$ is advertising. The author of this reading has information and ideas about advertising to share with her readers. The most important idea that the author wants to communicate about the topic is called the main idea.

What is the main idea of this reading? Is the main idea stated in the reading? If so, where?

B. On your own. How does the writer organize her ideas. Reread pages $98-99$ and take notes in this chart.

\begin{tabular}{|ll|}
\hline PARAGRAPH & \\
\hline 1 & TOPIC (what is the paragraph about!) \\
\hline 2 & Three levels of emotion that adds appeal to... \\
\hline 3 & \\
\hline 4 & \\
\hline 5 & \\
\hline Compare charts with your classmates
\end{tabular}

Multicultural Workshop-Book I, Heinle\& Heinle. ( p. 100) 
Using information from a text to label a diagram.

Use a sunshine outline like the one below to summarize the story of the Navajo Code talkers.

Who were the Navajo Code talkers?

What did they do?

When did they use the code?

Where were they when they used the code?

Why were they needed?

How do you think the code worked?

How long did they keep the secret of the code?

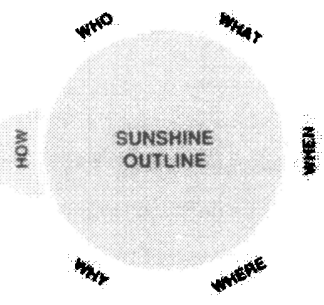

Voices in literature, Heinle \& Heinle. ( p. 105)

\section{I.2 INTERPERSONAL STRATEGIES}

\section{- COOPERATING}

When we cooperate, we share ideas with other students. It is particularly effective in language learning, because students are required to communicate with each other in order to cooperate.

Oxford (1990) says cooperation comes in many forms. The learner does well to learn to cooperate with the teacher, with fellow students, and with native speakers of the language who are not connected with the classroom situation.

Cooperating with peers in the classroom is a special instance of cooperation. It 
involves either a cooperative task structure, in which group or team participants work together on aspects of the same task, or sometimes a cooperative reward structure, in which participants receive a common reward support (Slavin 1983, Kagan 1986, kohn 1987)

Many studies outside the language field have demonstrated the benefits of cooperation in the classroom: higher self-esteem, increased confidence and enjoyment; more respect for the teacher, the school, and the subject; greater and more rapid achievement; use of higher level cognitive strategies; decreased prejudice; and increased altruism and mutual concern (Oxford 1990).

In the language area, classroom cooperation has the following additional advantages: stronger motivation, increased satisfaction for teachers and students, more language practice, more feedback about language errors, and greater use of varied language functions. Cooperation is the principle which underlies many recent language teaching methods and approaches, such as Community Language Learning, the Natural Approach and Task-based Approach.

TASK

1. Work in groups. You are going to plan a dream holiday (money is no problem). Decide together which holiday you would like to go on, and why.

2. a) Read the fact file about your holiday (Safari page 140, European cities page 146, Florida page 146) and complete the tables.

b) Discuss the different possibilities.

3. Work with a new partner who has planned a different holiday from you. Ask/ tell each other about the holiday you have planned.

Cutting Egde Pre-Intermediate. Longman. (Page 53)

\section{- ROLE-PLAYING}

Pretending to be somebody else and using the language for the situation you are in. Example: You are a reporter. Use the information from the reading to interview the writer. 


\section{SOAP OPERA SCRIPT}

Imagine that you are the writers of a television soap opera similar to those described on page 128. Look back at the problems on pages 126-127. Write a scene from a soap opera based on one of them in which the characters discuss their problems, like the one below. Remember to include:

A the characters in the scene and a short description of each one.

B where / when the scene happens (location).

C stage directions telling the actors what to do and how to say their lines.

When you have finished, act out your scene to the rest of the class.

Cutting Egde Intermediate. Longman. (Page 129)

\section{I.3 LINGUISTIC STRATEGIES}

\section{- CONVERSATIONAL PATTERNS}

Using expressions to start conversations and keep them going. Example: Match formulaic expressions to situations.

Recognising and using formulas and patterns in the target language greatly enhance the learner's comprehension and production. Formulas are unanalysed expressions, while patterns have at least one slot that can be filled with an alternative word. It is very useful to teach students such expressions early in their language learning process. These routines will help build self-confidence, increase undestanding, and enhance fluency. Some formulas are most often used for the express purpose of managing conversations. Teaching learners to recognize these formulas as used by native speakers, and to use these formulas to continue in a conversation or show interest can be very beneficial. 


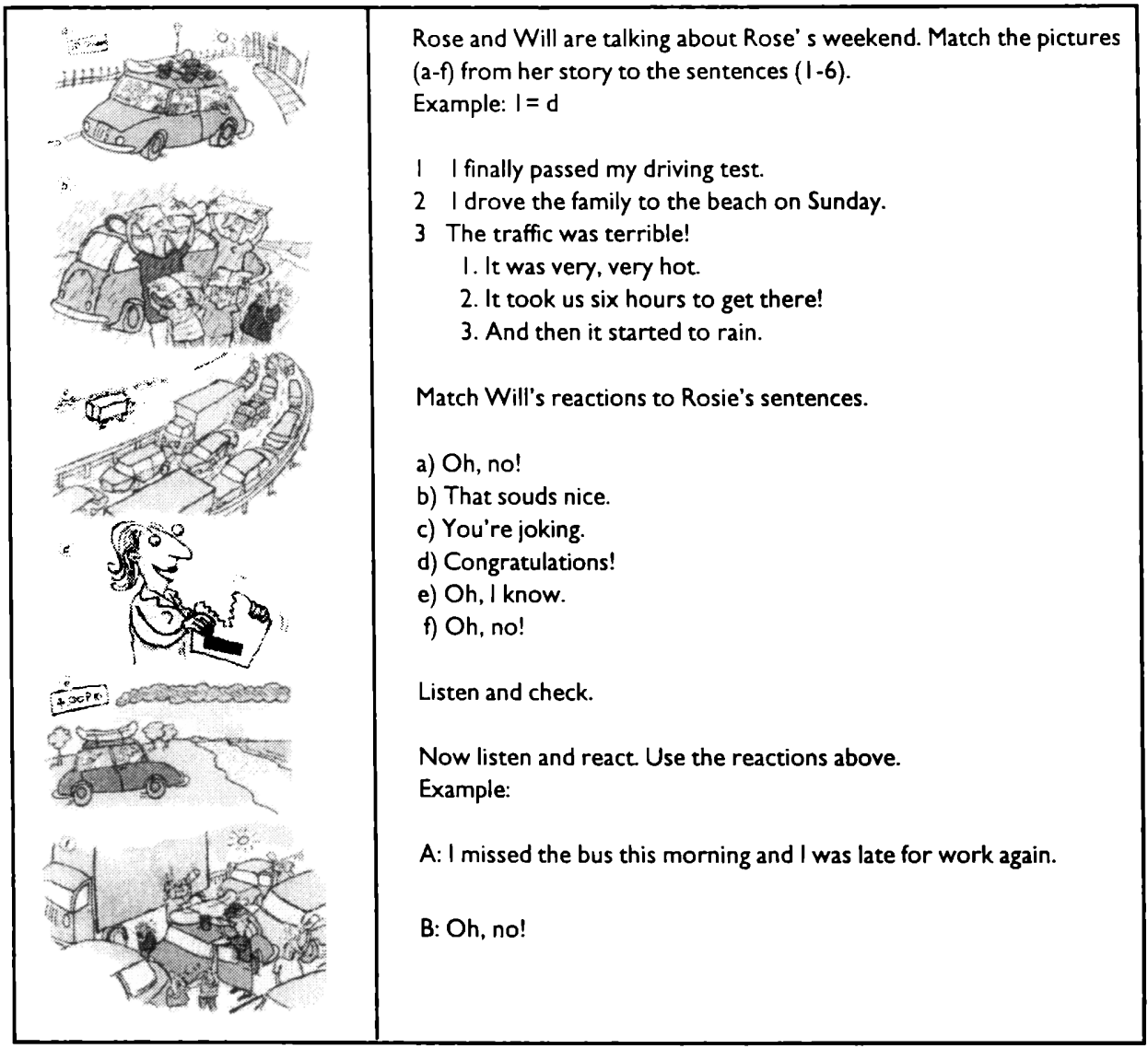

Wavelength Elementary, Longman. (Page 62)

\section{PRACTISING}

An essential strategy for developing skills is practising. Practising means doing controlled exercises to improve knowledge and skills.

Learners do not always realize how essential practice is. During class, potential practice opportunities are often missed. Even when small group activities increase the amount of classroom practice, still more practice is usually needed to reach, acceptable proficiency. Given these facts, the practicing strategies - including repeating, practicing with sounds and writing systems, recombining and practicing naturalistically - take on special value. 
Rebecca Oxford (1990) subdivides practising strategies into the following categories:

\section{REPEATING}

Saying or doing something over and over. listening to something several times; rehearsing, imitating a native speaker.

2. FORMALLY PRACTICING WITH SOUNDS AND WRITING SYSTEMS

Practicing sounds (pronunciation, intonation, register, etc.) in a variety of ways, but not yet in naturalistic communicative practice; or practicing the writing system of the target language.

3. RECOMBINING

Combining known elements in new ways to produce a longer sequence, as in linking one phrase with another in a whole sentence.

4. PRACTICING NATURALISTICALLY

Practicing the new language in natural, realistic settings, as in participating in a conversation, reading a book or article, listening to a lecture, or writing a letter in the new language.

Example:

2. FORMALLY PRACTICING WITH SOUNDS

PRONUNCIATION

When you use the Present Perfect tenses in speech, you use contractions and weak forms for has / have and been. However, you should not omit these auxiliary verbs altogether.

Practice saying the sentences above pronouncing the weak forms and contractions correctly.

/its bin snduin/

It's been snowing.

Cutting Egde Upper- Intermediate. Longman. (Page 59) 
It means sing the surrounding context to guess the meaning of unknown words, phrases, and concepts.

These sentences are from An Wang's biography. Use context-the other words in the sentences- to help you guess the meaning of each boldfaced word. Then compare guesses with your classmates.

a. On his way home from school one day. An Wang found a bird's nest that had fallen from the tree. Inside the nest was a baby sparrow.

My guess:

b. It was at this time that he invented the magnetic core. This device was a basic part of computer memory until the use of microchips in the late 1960s.

My guess:

c. In 1951 Wang decided that he was tired of working for other people. With his savings of $\$ 600$ he started his own company, Wang Laboratories.

My guess:

Multicultural Workshop-Book I, Heinle\& Heinle. (page 28)

- SUMMARISING

It involves picking out and presenting the major points in a text in summary form. This strategy helps learners structure new input and show they understand. Writing a summary can be challenging, because it often requires greater condensation of thought.

At the early stages of language learning, summarising can be a-s simple as just giving a title to what has been heard or read; the title functions as a kind of summary of the story or passage. Another easy way to summarise is to place pictures which depict a series of events in the order in which they occur in the story. This is a very useful exercise, especially for beginners, because it links the verbal with the visual.

As students advance in their knowledge of the target language, their summaries can be made in the target language, thus allowing more writing practice. The summaries they construct can also become more complex; for example, learners can write complete sentences or paragraphs (called an 'abstract') summarizing what they have heard or read. 
In the diagram below, summarize the story. Tell only the most important things that happened.

STORYPLOT(WHATHAPPENED!)

\begin{tabular}{|c|}
\hline INTHE BEGINNING \\
\hline$\downarrow$ \\
\hline IN THE MIDDLE \\
\hline$\downarrow$ \\
\hline IN THE END \\
\hline
\end{tabular}

Compare diagrams with your classmates.

Multicultural Workshop-Book /, Heinle\& Heinle.( page 20)

\section{- SELECTIVE LISTENING}

A key strategy for learners is listening for key information without trying to understand every word. This strategy is essential if learners are to cope effectively in genuine communicative situations outside the classroom. It is important for learners to realize that native speakers use this strategy quite naturally when communicating with one another, that it is, in fact, impossible as well as unnecessary to process every single word in most listening situations.

Example:

Buying clothes

Pieter's at the Levi store. Listen. What does he buy?

\begin{tabular}{|c|c|}
\hline 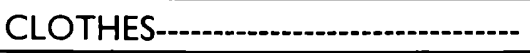 & COLOUR-1- \\
\hline 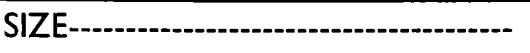 & 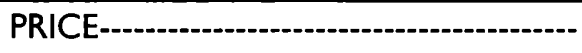 \\
\hline
\end{tabular}

English File 2 Oxford University Press. 1997. (Page 86)

- SKIMMING

Reading quickly to get a general idea of a text.

Example: Decide if the text is a newspaper article, a letter, or an advertisement. 
- SCANNING

Reading quickly to find specific information.

Example:

Quickly read the newspaper article. Where exactly is Pascale?

FRENCH TOURIST MISSING IN SNOWDONIA

A young French woman, Pascle Hartman, aged 24, is missing in north-west Wales after two days of strong winds and heavy snow. She was last seen at I 1:45 on Friday morning when she left the Youth Hostel to go climbing. A mountain rescue tems is looking for her.

English File 2 Oxford University Press. 1997. (Page 43)

\section{I.4 CREATIVE STRATEGIES}

\section{BRAINSTORMING}

It means thinking of new words and developing ideas quickly.

Example: Work in a group and think of as many occupations as you can.

Brainstorming is a good way to collect ideas for writing. It is an especially useful strategy to use with a partner or with a group of people.

The following steps can be used to brainstorm a set of ideas.

1. Put your writing idea on a piece of paper. This might be a word, a phrase, or a question.

2. Write down every word that comes to mind. Don't evaluate your ideas. Just think and write quickly. 
Example:

Group work. Brainstorm answers to the question below. Choose one person to report your group's answers to the class.

In your opinion when is a person "old"?

$$
\begin{aligned}
& \text { GROWING OLD } \\
& \text { gray hair } \\
& \text { hard of hearing } \\
& \text { tired } \\
& \text { fun } \\
& \text { slow down } \\
& \text { less work } \\
& \text { meet friends }
\end{aligned}
$$

After brainstorming, reread your list and circle the ideas you might want to use in your writing.

Multicultura/ Workshop-Book I, Heinle\& Heinle (page 169)

\subsubsection{AFFECTIVE STRATEGIES}

They include tasks which have no specific language learning goal but are intended to improve the motivational climate of the classroom and to develop the students' interest, confidence, and positive attitudes toward learning. For example, students may keep a journal in which they write about their feelings, fears, and satisfactions in relation to the experiences they have in the class. They may share these both with their classmates and the teacher, and attempt to resolve concerns as they arise.

\section{- PERSONALIZING}

Learners share their own opinions, feelings, and ideas about a subject.

\section{Example:}

Group work. List the advantages and disadvantages of old age. Then add your ideas to a class list on the board.

\begin{tabular}{|c|c|}
\hline ADVANTAGES & DISADVANTAGES \\
\hline+ & - \\
\hline & \\
\hline
\end{tabular}

Multicultural Workshop-Book I, Heinle\& Heinle (page 169) 


\section{REFLECTING}

It involves encouraging learners to think about ways they can learn best. Learners should experiment to see if some tasks are better accomplished by using the eye, while others are better accomplished with the ear. For example, they may find that listening to tapes helps them improve their oral comprehension. Others may retain vocabulary better if they use flash cards. We should remind students that applying the same strategy to all tasks will not work.

\section{ENCOURAGING LEARNER INDEPENDENCE}

\section{I GOAL SETTING}

Making goals explicit has a number of pedagogical advantages. First, it helps to focus the attention of the learner on the tasks to come and this enhances motivation.

Teachers should aid their students in determining goals and objectives. The learners' chances for successfully learning a foreign language are further enhanced if they take charge of the situation: that is, if they determine their own goals and objectives. It is important for students to set realistic goals. Very often people do not have a clear idea of how complex learning a language is, they often expect to understand, speak, read, and write a foreign language after a relatively short period of study. When they find themselves unable to communicate with native speakers, unable to write a business letter, unable to read a newspaper article or to follow a TV or radio programme, they often become disillusioned and blame themselves, the teachers or the textbook for their lack of success. Consequently, they may acquire a negative attitude toward foreign language study in general. Such negative outcomes can be avoided if learners realise that language learning entails a series of stages of achievement from the simple to the more complex, and that success at each stage requires a certain amount of practice in the skills they want to acquire. Learners should structure their approach and measure their success accordingly. By setting realistic objectives they can more easily sustain their motivation and interest.

\subsection{SELF-EVALUATING}

Many language teaching programmes are based on learners performing certain tasks which the teacher sets and then evaluates. Teachers normally give learners information about their progress in various ways, for example, through the use of grades or test results. However, we would see it as equally important to foster the ability to self- 
evaluate if we are to produce autonomous learners. In order to mediate in this way, the teacher needs to identify ways in which learners can be helped to become more aware of their own progress.

Self-evaluating involves thinking about how well you have done on a learning task, and rating yourself on a scale. By having learners rate themselves against their learning goals, the teacher not only develops the learners' self-critical faculties, but also serves to remind them of the goals of the instructional process. A major reason for carrying out self-evaluation is to determine whether learners are progressing satisfactorily or not, and, if they are not, to diagnose the cause or causes and suggest remedies. Self-assessment strategies also help learners identify preferred materials and ways of learning. They can be involved in evaluating their own progress, the learning activities used, the learning modes and so on.

The students' self awareness can also be developed by using self-evaluation scales as the ones shown below.

\section{SELF-EVALUATION OF PROFICIENCY}

\begin{tabular}{|l|l|l|l|}
\hline 1 & I can ask for factual information & YES & NO \\
\hline 2 & I can provide personal details. & YES & NO \\
\hline 3 & I can understand weather forecasts on the radio. & YES & NO \\
\hline 4 & I can read public notices. & YES & NO \\
\hline
\end{tabular}

Self-evaluation of learning activities

Tick the box

\begin{tabular}{|l|l|l|l|}
\hline ACTIVITY & I LIKE & IT'S OK & I DON'T LIKE \\
\hline Listening to authentic conversations & & & \\
\hline Watching the TV news & & & \\
\hline Singing songs & & & \\
\hline Doing grammar & & & \\
\hline Doing pronunciation & & & \\
\hline Doing group work & & & \\
\hline Doing role-plays & & & \\
\hline Playing games & & & \\
\hline Writing letters & & & \\
\hline Reading the newspaper & & & \\
\hline
\end{tabular}




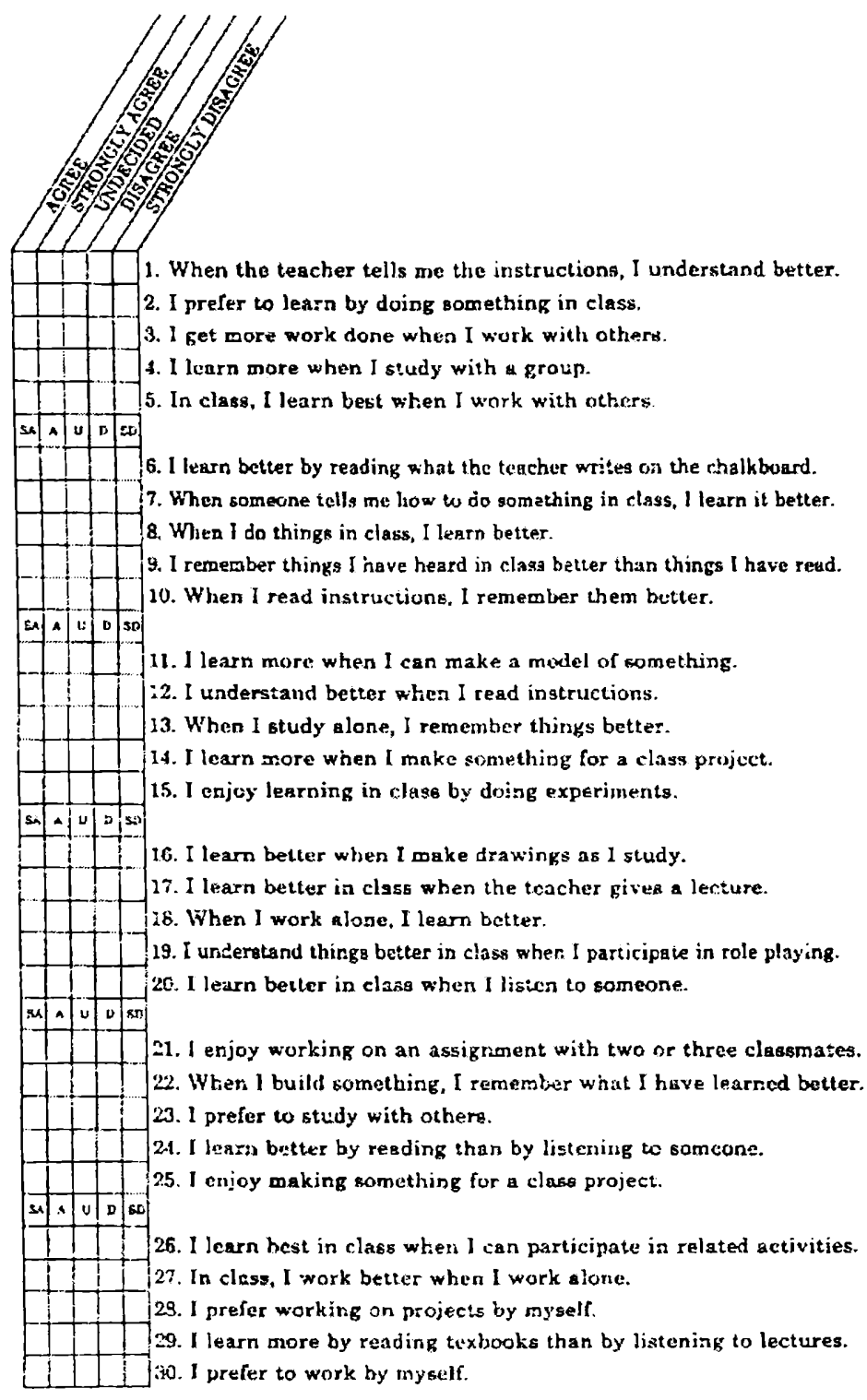

Taken from Richards and Lockhart. Reflective Teaching in Second Language Classrooms. CUP, 1994. 


\section{Intruedtens:}

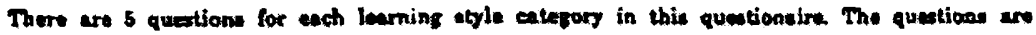
Erouped below cecordipg to each learning style. Each quention you unwrer hes a numerial value 1

\begin{tabular}{|c|c|c|c|c|}
\hline SA & A & U & D & SD \\
\hline 6 & 4 & 3 & 2 & 1 \\
\hline
\end{tabular}

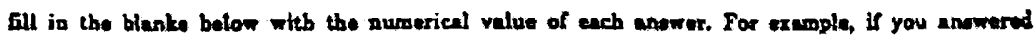

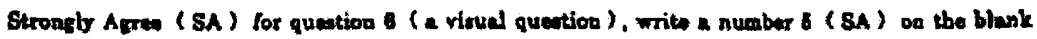
mext to quention $\theta$ below.

$$
\frac{\text { Vient }}{6-5}
$$

When you have completed sll the numerical valuee for Visual, add the byrobers. Multiply the anower by 2, ead put tho total in the epporpriets blank.

Follow this proces for each of the learning style entugarien. When you are friched loak at the seale at the bottor of the page 1 it will help you detersine your major leuming etylo proforesce (a).

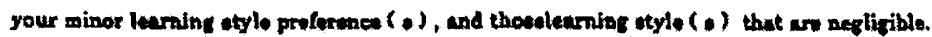

If you need belp, piouse ask your toucher.

\section{VISUAL}

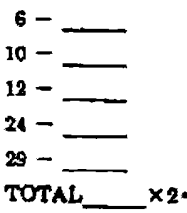

AURTTRYY

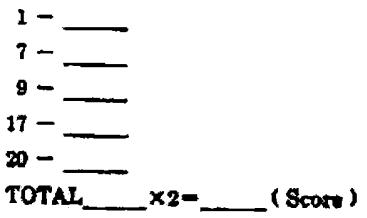

XINESTHETC

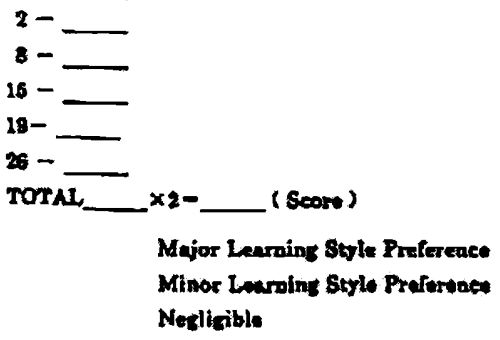

\section{TACTILE}

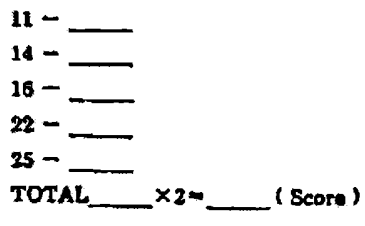

GROUP

$$
\begin{aligned}
& \text { 3- } \\
& \text { 1- } \\
& 5- \\
& \text { 2X - } \\
& 23 \text { - }
\end{aligned}
$$

\section{INPIVIDUAk}

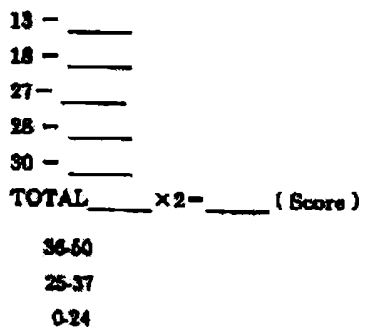

Taken from Richards and Lockhart. Reflective Teaching in Second Language Classrooms. CUP, 1994. 
An important consequence of learning how to monitor one's own progress in learning is that one comes to recognise personal change as continuous, lifelong and within one's own power. The issue then becomes not whether or not to change, but what degree of personal influence we choose to exert on that change. Several educators have argued that in preparing young people to cope with a world of rapid and unpredictable change, the recognition of the importance of change as a process in itself becomes one of the central tasks in education. Toffler (1970) and Handy (1989) are just two of the growing number of commentators who argue that our whole education system must change in the direction of teaching people to learn how to learn and become flexible thinkers in order to prepare them to cope with this world of continuous change.

\subsection{LEARNER CHOICE}

The difference between an effective and an ineffective language learner is that effective language users make the appropriate choices when it comes to the linguistic options available to them. (This applies to native speakers as well as to second language learners.) Encouraging learners to make choices is an important aspect of learner inde-

pendence. We can help learners develop skills in making appropriate choices by giving them practice in doing so in the security of our classrooms. Examples of choices learners can make may include the following: whether to work in groups or in pairs for a particular task, whether a particular writing task should be done in or out of class, whether a particular task would be completed individually and then shared in groups, or whether it should be done as a group task from scratch, whether a series of reflection sheets should be completed every week or every two weeks, etc. By encouraging learners to make choices in our classrooms and in the teaching materials we provide for them, we convey to our students the important message that they have responsibility for making decisions and taking control of their learning. Moreover, by highlighting these points for discussion, and by looking for opportunities to weave them into the fabric of one's teaching, the whole climate of the classroom can be gradually transformed.

\subsection{CAUSES OF LEARNER FAILURE}

It is expected that learners who could be described as 'advanced' (First Certificate level) are already aware of which learning strategies work well for them. However, we often find students at these levels who have difficulties in achieving a task successfully. Studies of successful and unsuccessful learners (Chamot, O'Malley. 1987) have shown that people who succeed in learning have developed a range of strategies from which 
they are able to select those that are the most appropriate for a particular problem. Thus, for effective learning to take place, what is important is the learners' ability to respond to the particular learning situation and to manage their learning in an appropriate way.

\subsection{CASE STUDY}

The following study carried out by David Nunan (1988) was designed to investigate teacher attitudes toward the failure of learners to achieve programme goals. The study gives as the first cause of learner failure the use of inefficient learning strategies.

\section{Background}

Assessing learner achievement (or lack thereof) is only the first step in the evaluation process. It is highly unlikely that all learners will make satisfactory progress all of the time (if they do, it is likely that the course is too easy for the group). In cases of failure to achieve objectives, the next step is to diagnose the likely cause or causes, and to suggest remedies.

There are many different possible causes of learner failure. Some of the more common of these, which have been reported by teachers, are the following:

I Inefficient learning strategies.

2 Poor attention in class.

3 Irregular attendance

4 Particular macroskill problems.

5 Difficulty with discrete language points.

6 Failure to use the language out of class.

7 Faulty teaching techniques.

8 Objectives inappropriate for learners.

9 Materials / learning activities inappropriate for learners.

10 Learner attitude.

II Personal (non-language) problems of learners (including physical disability).

The study

In order to obtain more detailed information about the causes of learner failure, the questionnaire shown below was circulated to a group of teachers taking part in a workshop. 


\section{Survey results of causes of learner failure}

\begin{tabular}{|lll|}
\hline Cause & $\begin{array}{c}\text { Number of teachers rating } \\
\text { this as a cause of failure }\end{array}$ & $\%$ \\
\hline Causes attributable to the learner & & \\
\hline Inefficient learning strategies & 26 & 77 \\
\hline Failure to use the language out of class & 26 & 77 \\
\hline Irregular attendance & 15 & 45 \\
\hline Particular macroskill problems & 11 & 32 \\
\hline Poor attention in class & 3 & 9 \\
\hline Personal (non-language) problems & 3 & 9 \\
\hline Learner attitude & 1 & 4 \\
\hline Causes attributable to the teacher & & 32 \\
\hline Inappropriate learning activities & 11 & 27 \\
\hline Inappropriate objectives & 9 & 23 \\
\hline Faulty teaching & 8 & 145 \\
\hline
\end{tabular}

Taken from Nunan, David (1988) The Learner-centred Curriculum, page 145.

From the data it can be seen that the teachers surveyed placed responsibility for failure firmly with the learners. However, it is worth noting that, in relation to causes attributable to the teacher, one third of those surveyed identified inappropriate learning activities as a possible cause, and approximately a quarter identified inappropriate objectives and faulty teaching as having a significant effect on learning outcomes.

Systematic observation is one way in which teachers can diagnose which of the above reasons are implicated in learner failure. Non-observable problems, such as failure to use the language outside class, can be diagnosed through learner diaries and reports. Interviewing learners from time to time can also help build up a picture of the learner's preferences, strengths and weaknesses. Such interviews can canvass the following issues:

Which lessons / parts of lessons have been most useful?

Which things have you learned so far?

What helped you learn?

How do you learn best?

Have your ideas about how you learn changed? How? 
Do you enjoy having different teachers?

Do you come to class as often as you can?

Why have you missed some classes?

Having diagnosed problems, the teacher can develop strategies to overcome them. These need not always entail changing the learner. It may well be that objectives, methods, materials and learning arrangements should be changed to accommodate learners. There are of course some causes, such as personal problems learners are having outside class, which teachers may be incapable of changing.

\section{INTRODUCING STRATEGIES IN THE CLASSROOM}

In this section I shall look at some of the ways in which strategies can be introduced into the classroom. It is important to keep in mind that, as far as possible, strategies should be integrated into the ongoing process of the language lesson.

\subsection{A SAMPLE LESSON}

Here is an example of a class I gave at Colegio Nacional "Rafael Hernandez", La Plata. The aim of the lesson was to illustrate examples of learning strategies for developing the four language skills (listening, speaking, reading and writing).

The activities selected for this class were topic-centered (connected to the topic of the story: Message in a bott/e). Considering that one of the factors that may influence the choice of strategies is "the requirements of a task" I planned the strategies I wanted students to develop and according to them I chose the activities (not all of them were included in the textbook).

Skills:

Listening. a guided fantasy and a song.

Speaking: retelling of sensations, feelings and emotions, students had experienced while listening to the guided fantasy. I asked students to retell the story once they had finished doing the jigsaw reading activity.

Reading: a story called "Message in a bottle" through a jigsaw reading activity. Writing: a written assignment to be done as homework. Write a message to be put in a bottle.

Ist ACTIVITY: a guided fantasy called "A deserted beach" accompanied with music. I 
elicited from students the type of strategies to be developed and the purpose:

Type of strategy:

I- Lowering anxiety. (Affective strategy)

2- Preview already known material for an upcoming language activity. (Metacognitive strategy), since the topic of the guided fantasy is related to the story students will read.

Purpose:

To create a relaxed atmosphere in the classroom.

To make students forget about worries; to relieve stress.

To help students to relax; to get rid of negative feelings such as tension by listening to a soothing melody and by making them imagine the ideal place to feel at ease with themselves

Follow -up activity: After listening, I extended the activity by asking about feelings and sensations while doing it (colours, sounds, smells, tastes, activities, feelings)

Type of strategy: Affective

Purpose: give students an opportunity to talk about feelings and sensations.

$2^{\text {nd }}$ ACTIVITY: a lead-in activity with books closed.

Purpose: Link and preview already known material for an upcoming task.

Strategy: Use a mind map to overview ideas and to help students to elicit and to get the main idea.

The procedure I used was the following:

I drew the central circle of this word map on the b/b; eliciting from students as many ways to communicate as possible.

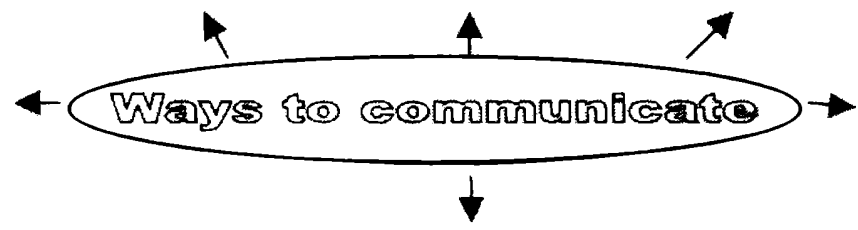

After this, I introduced the situation: Imagine you are on a desert island. How could 
you communicate?

Eliciting: by sending a message in a bottle.

$3^{\text {rd }}$ ACTIVITY: With books open. Students covered the text and looked only at the map and the photo.

Strategy: Guessing intelligently using non-linguistic clues (text structure, pictures and title)

$4^{4 h}$ ACTIVITY: Reading. I elicited different possibilities of dealing with the text:

Conclusion: students can either read the article and number the paragraphs in order from 1 to 6 or do a jigsaw reading activity where students working in pairs or small groups put together five pieces of a written text that have been separated, thus requiring that learners guess by using text structure and_content clues. In doing this, students have to use other strategies as well, such as, cognitive strategies (Analysing and reasoning and getting the idea quickly). After the task is done, the pairs/groups compare results with other pairs. Thus developing social strategies (collaborating with peers).

Teachers can make their students use certain strategies if they:

a) Set a time limit, thus encouraging students to get the idea quickly.

b) If students ask for the meaning of new words, remind them to use efficient word attack strategies_such as:

- Pay attention to cognates and borrowings.

- Look for familiar elements in new words.

- Don't demand an exact meaning for every word, guess through context. Read the whole sentence. Look at the larger context.

- Some grammatical categories are particularly important:

Learn rules of word order.

Learn prepositions.

Look for discourse markers.

Look for words that refer to other words.

Use resources e.g.: a dictionary. 
c) Make students work with each paragraph, eliciting different techniques for doing so (comprehension questions, true or false, multiple choice) to:

- get the main idea.

- Summarise.

The following are different kinds of follow-up activities suggested for this lesson:

- a project work, sending balloons containing messages inside

- written assignments for homework

- a pop song by The Police called "Message in a bottle".

$5^{\text {ch }}$ ACTIVITY: Write a message in a bottle to the outside world.

Students were given the following situation to write their messages:

Imagine you are shipwrecked on a desert island and you want to send a message in a bottle to the outside world asking to be rescued.

We discussed strategies for developing writing skills, especially those students can use to get ideas for writing their messages:

Some suggestions:

Mind map. Write island in the middle of a piece of paper and write down all other words that island suggests at suitable places on the mind map.

Brainstorming. Make quick notes about anything that comes into your head about the situation on the island e.g.: can't swim, don't like fish, tell mother, wonderful suntan, miss favourite TV program.

Asking questions. Write down the questions that the reader of your message might want to ask e.g.: How long have you been on the island? Are you alone? Is it dangerous there? What do you eat? How do you spend your time?

After showing different techniques to get ideas, students should decide which ones they will use and which order they will write them in. Plan before writing: consider the function of each sentence in light of its relation to the main topic in order to provide readers with a clear sense of purpose. 
$6^{\text {ch }}$ ACTIVITY: Listen to a song

Listening activity to make students develop the following strategies:

Practice naturalistically

Listening with a purpose using the following techniques:

To focus on vocabulary through a fill in the gaps activity.

To get the main idea.

Focus question: What's the song about?

Multiple choice exercise.

\section{STRATEGIES GROUPED ACCORDING TO THE FOUR LANGUAGE SKILLS}

Although the primary aim of this paper, as its title suggests, is on Language Learning strategies, i.e. teaching learners how to learn the formal/ grammatical system, I will also refer in this section to the development of strategies grouped according to the four language skills.

\section{I Learner training and study skills}

In recent years there has also been a growing interest in the area of study skills. Study skills for EFL and ESL, or English for Academic Purposes (EAP) equip learners with the skills required in order to succeed in a particular study environment. For example, a course which prepares foreign students for study at a British university requires students to be proficient in such skills as taking notes as they read a book or listen to a lecture, preparing for seminars, organizing and presenting essays (Wallace 1980), where training students to develop the four skills of the language (reading, listening, speaking and writing) is essential.

It is often claimed that the aims of study skills are very similar to those of learner training (Ellis and Sinclair 1989). However, the most significant differences between them are:

a. In study skills, objectives are usually imposed from some external source, such as a set syllabus. Learner training provides learners with more opportunity to select their own learning objectives. 
b. Study skills tend to focus on the particular products required by a specific study context. such as passing examinations or writing a good essay. Learner training focuses on the process of learning in order to provide learners with wider insights into their own learning.

c. Study skills tend to involve learners in specific tasks or activities directly related to the requirements of their course of study, such as developing reading strategies that will enable learners to read a test in the foreign language. Learner training tends to provide more opportunities for learners to reflect on their attitudes towards themselves as learners and their personal learning preferences, as well as to experiment with different learning and practice activities in general.

d. Study skills usually prepare learners for an external system of assessment. Learner training trains in self-assessment.

In order to help learners to be skillful users of the language, it is important to develop the so-called 'four skills' -listening, speaking, reading and writing-. The interest of this section is in the development of the learners' facility in receiving and conveying messages by means of strategy training.

\subsection{TOWARDS IMPROVING THE STUDENTS' READING COMPREHENSION}

Just giving students large quantities of reading materials does not guarantee that they will improve their reading skills. To improve their reading abilities, students must develop their comprehension skills. Most beginning learners have difficulty understanding their texts because they pay attention to the literal meaning of the words rather than try to understand the overall meaning. A variety of teaching strategies can be used to improve the learners' reading comprehension. Teachers need to help students guess at meanings first by using context. They can also assure students that they do not have to understand every word to understand the main idea. Beginning learners also need contextual supports to understand the authentic texts they read. For instance, pictures and diagrams can illustrate key vocabulary effectively. When selecting authentic texts for beginning students, efforts must be made to find topics that are at least partly familiar to the students. Sometimes students do not have enough knowledge of the world to understand certain kinds of text and teachers must fill them in on what they need to know to comprehend the reading. Teachers need to focus on those concepts that are central to understanding the upcoming reading, concepts that learners either do not possess or may not think of without prompting. To this end, pre-reading activities are 
beneficial. Stoller (1986) suggests that reading be preceded by pre-reading activities in which the teacher:

I. asks students to focus on the title and any illustrations that may accompany the text;

2. asks students to skim the entire passage quickly for the main idea;

3. asks students to scan the passage for specific details considered crucial for overall comprehension;

4. introduces loaded cultural presuppositions which would otherwise mislead or confuse students, or perhaps go unnoticed.

Students can read in depth to increase their comprehension of the reading passage. This is called intensive or narrow reading. When students read narrowly (reading, for example, books by the same author or several texts about the same topic), grammatical and discoursal structures repeat themselves so that students get many chances to understand the meanings of the texts they read (Krashen and Terrell 1983).

In extensive reading, students do not need to understand all the details of the text. Instead speed and skill in getting the overall gist of the text are important. Good readers in both a first and second language use a wide variety of strategies to adjust to the material they read. Teachers need to design activities that develop all of the strategies needed to read a variety of texts effectively. While some adult learners are capable of developing effective reading strategies just by increasing the amount they read, others are not. For this reason, we should help our students in the use of effective reading strategies.

\subsection{READING STRATEGIES}

It is now standard practice in the design of reading tasks to use a three-phase procedure involving pre-, while-, and post reading stages (Williams 1984). The intention is to ensure that reading is 'taught' in the sense of helping readers develop increasing ability to tackle texts. 
PRE-READING STRATEGIES

\section{ANTICIPATION}

Motivation is of great importance when reading. Partly because most of what we read is what we want to read, but also because being motivated means that we start reading the text prepared to find a number of things in it, expecting to find answers to a number of questions and specific information or ideas we are interested in. This expectation is inherent in the process of reading which is a permanent interrelationship between the reader and the text. What we already know about the subject and what we are looking for are probably just as important as what we actually draw from the text. When reading, we keep making predictions which, in their turn, will be confirmed or corrected.

This underlines the artificiality of the classroom situation in which students are often confronted with passages they know nothing about, or have no particular desire to read. It is very difficult, in such conditions, to expect the students to learn to read better. The practice of letting the students choose the topics they wish to read about should therefore be encouraged.

Before the students start reading a text, they can always be asked to look for the answers to specific questions. This will give an incentive to their reading activity.

For example:

- Psychological sensitising aimed at making the students think about the subject of the text and ask themselves questions.

- Using the title and pictures to talk about the various ways the text may develop.

- Using the key- words of the text to predict content.

\section{PREVIEWING}

Previewing involves using the table of contents, the appendix, preface, the chapter and paragraph headings in order to find out where the required information is likely to be.

To preview an article or story, you look over the whole reading before you start to read.

Examples:

- Look at the title and ask questions about it.

- Look at the pictures and predict what the article or story is about.

- Set a purpose for reading. Decide what you hope to find out as you read.

- Recall what you already know about the topic. 
- Read the first paragraph and the last paragraph and try to figure out the main idea of the reading.

\section{WHILE-READING STRATEGIES}

\section{PREDICTING}

Predicting is the faculty of guessing what is to come next, making use of grammatical, logical and cultural clues. We can train students to make predictions by giving students unfinished passages to complete or by going through a text little by little, stopping after each sentence in order to predict what is likely to come next.

You make predictions when you answer questions such as these: What is the next paragraph in this reading going to be about? Or what is going to happen to the main character in this story?

When you make a prediction, you use what you already know about a topic, person, or event. Using what you already know helps you to make a logical prediction.

\section{FINDING MAIN IDEAS}

Main ideas are the central or most important ideas that a writer wants to communicate. A text may have many related ideas, but one or two ideas are usually the most important.

Sometimes the main idea is stated directly in a paragraph. The sentence that states the main idea is called the topic sentence.

\section{MAKING A STORY OUTLINE}

Making a story outline helps you to focus on important information in a story. When you make a story outline, look for these main parts of a story:

Characters. Who are the people in the story?

Setting. Where and when does the story take place?

The problem or conflict. What is the central issue? What are the characters trying to do?

Important events. What happens in the story? 


\section{SEMANTIC MAPPING}

Sometimes called word-webbing or clustering, is a different way students can improve their reading comprehension. When students map, they write down anything and everything they think of when they read a given passage. During this time, they make web diagrams, connecting their ideas in such a way that they display interrelationships within and across subtopics of the reading. Students can write the core concept in the centre and then connect details to the main concept.

\section{MAKING INFERENCES}

Inferring means making use of syntactic, logical and cultural clues to discover the meaning of unknown elements.

When dealing with a new text, it is better not to explain the difficult words to the learners beforehand. They would only get used to being given 'pre-processed' texts and would never make the effort to cope with a difficult passage on their own. On the contrary, students should be encouraged to make a guess at the meaning of the words they do not know rather than look them up in the dictionary. If they need to look at the dictionary to get a precise meaning -which is an important and necessary activity toothey should only do so after having tried to work out a solution on their own. This is why, from the very beginning, it is vital to develop the skill of inference.

\section{PARAPHRASING}

When you paraphrase, you put information and ideas into your own words. Paraphrasing is a good way to check your understanding of written material. It can also help you remember ideas and information.

\section{SKIMMING AND SCANNING}

Both skimming and scanning are specific reading strategies necessary for quick and efficient reading.

When skimming, we go through the reading material quickly in order to get the gist of it, to know how it is organised, or to get an idea of the tone or the intention of the writer.

When scanning, we only try to locate specific information and often do not even follow the linearity of the passage to do so. We simply let our eyes wander over the text until we find what we are looking for, a name, a date, or a less specific piece of 
information.

Skimming is therefore a more thorough activity which requires an overall view of the text and implies a definite reading competence. Scanning, on the contrary, is far more limited since it only means retrieving what information is relevant to our purpose. Yet it is usual to make use of these two strategies together when reading a given text. For instance, we may well skim through an article first just to know whether it is worth reading, then read it through more carefully because we have decided that it is of interest. It is also possible afterwards to scan the same article in order to note down a figure or a name which we particularly want to remember.

\section{SUMMARISNG}

When you summarize, you restate ideas and information briefly in your own words. A summary gives only the most important ideas and information.

\section{TAKING NOTES IN A CHART}

Taking notes as you read helps you to organize and remember important information. When students take notes, they should write down the most important information only.

Here is one type of chart students might use:

\begin{tabular}{|l|l|}
\hline MAIN IDEAS & DETAILS \\
He had a difficult childhood. & $\begin{array}{l}\text { His parents died. } \\
\text { He lived through a civil war. } \\
\text { He didn't go to school. }\end{array}$ \\
\hline
\end{tabular}

\subsection{WRITING STRATEGIES}

Since writing is primarily about organising information and communicating meaning, generating ideas is clearly a crucial part of the writing process. Because getting started is one of the most difficult steps in writing, idea-generating is particularly important as an initiating process. For this reason, the activities that follow can be regarded as belonging to the initial stages, when the writer is still attempting to discover a topic and identify a purpose. To assist in generating ideas at this initial stage, there are different kinds of discovery strategies. 


\section{BRAINSTORMING}

Brainstorming is a good way to collect ideas for writing. It is an especially useful strategy to use with a partner or with a group of people. Brainstorming involves thinking quickly and without inhibition so as to produce as many ideas as possible on a given topic or problem.

Procedure

- Before providing the topic, we should tell the students that they will spend about a minute or so silently writing down ideas by themselves before working in pairs and groups.

- Each student then starts off by writing their ideas. After a minute or so, they join with a partner and 'bounce' ideas off one another. Then get the pairs to join to make fours, and repeat the exchange of ideas and generation of new ones.

\section{QUICKWRITING}

Quickwriting is a useful way to collect ideas for writing.

Follow these steps to quickwrite:

- Choose a topic, something you want to write about.

- For five or ten minutes, write quickly. Don't worry about grammar or spelling. If you can't think of a word in English, write it in your native language. The important thing is to write without stopping.

- If you can't think of anything to write, put that down or write the same word over and over again.

When you have finished writing, read over your ideas. Circle the ideas that you like.

\section{ASKING QUESTIONS}

Questions are an important prompt for writers. One of the skills of a good writer is to think of interesting questions to ask because these yield interesting answers.

As with brainstorming, a topic can be given to students, who then use a series of questions to stimulate thinking, to draw on their experience and to develop and shape their ideas. It is important to realise that, as with any generating procedure, the aim is not to stifle creativity and individualism, but to promote both. Indeed, given the same set of questions, each individual in the class should come up with different answers. 
Furthermore, given the interactive nature of questions and answers, using questions as part of the writing process can stimulate a lot of valuable discussion and genuine communication among students.

\section{Procedure}

- Introduce the topic and ask students to suggest questions people might have about it.

- Having established an idea of what is wanted, ask students individually to write down at least three questions. Allow a couple of minutes for this.

- They join with a partner to compare questions and then, after a few minutes, form small groups to exchange ideas.

- Finally, have each student read out one question. Collect the questions on the board as they do this. They now have a pool of questions to answer and use as the basis for a written text.

Questions can also be used to stimulate the imagination by tapping the episodic and unconscious memory, particularly by drawing on the senses of hearing, sight, smell and touch. Using the senses helps to establish actuality, which is important in developing a sense of place and a credible story.

As an illustration of this strategy, I describe an activity I carried out with a group of advanced students to write a short story about travelling on the Buenos Aires subway.

These are the questions I used to get ideas going:

You are on the street in Buenos Aires:

What time of day is it?

What's the weather like?

What noises can you hear?

You go down into the subway:

What is your first reaction?

What smells are there?

What is the atmosphere? 
You see a crowd of people?

How are they moving?

Where are they going?

What does the crowd look like?

How do you react to being in the crowd?

You go into the platform:

What are the other travelers doing?

Someone looks at you. With what sort of

expression?

$\mathrm{He} / \mathrm{she}$ speaks to you. What does he/she

say?

What is your reaction?

Your train arrives:

What do you hear?

What do you smell?

How do you feel?

Continue the journey to your destination...

\section{MAKING NOTES}

Some schemes for note-taking such as the so-called 'spidergram' really result in a good display of information which can then be easily converted into a draft. Having a scheme or form of organization right at the start may help students to produce ideas. As note-taking is primarily concerned with generating ideas and secondly with organizing them, correctness and precision of language are not yet important considerations at this stage.

Making diagrams can also help students see the connection between big ideas and details.

In the following example, a student, writing a description of a person he admired, decided to arrange his notes in the form of a 'spidergram'. 


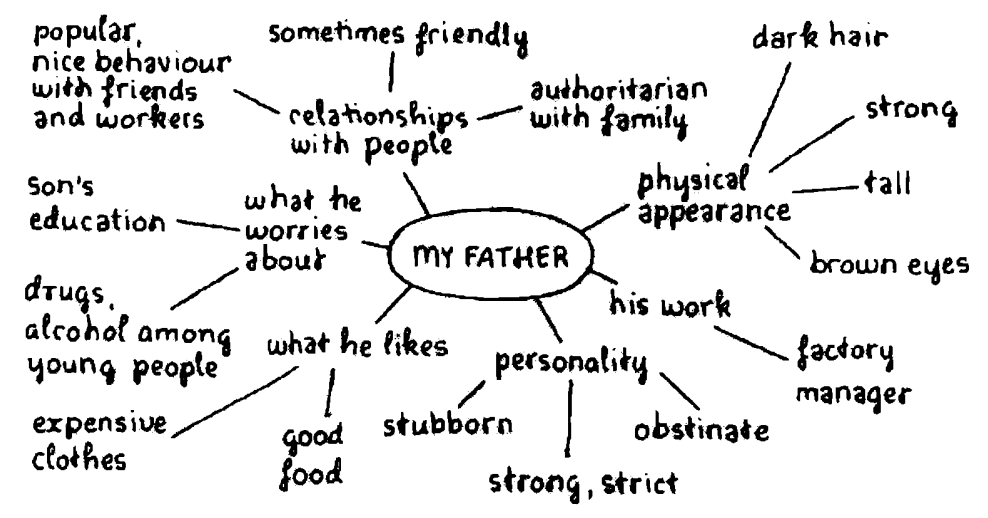

\section{MAKING A TREE DIAGRAM}

Making a tree diagram is a useful way to organize your ideas before you start writing. Before you make a tree diagram, you might want to first list ideas about your topic. Then reread your list of ideas looking for categories of information. Write these categories on your tree diagram. Then list ideas in each category.

Example:

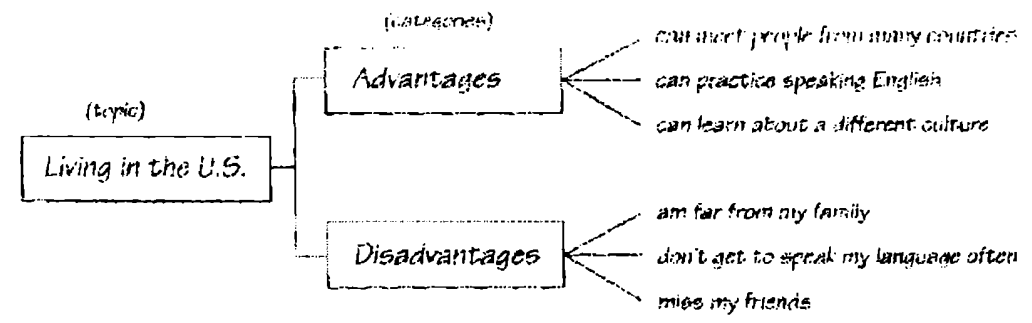

\section{MAKING A VENN DIAGRAM}

To compare and contrast two things, a Venn diagram can be used to collect ideas. In the centre of the diagram (where the circles overlap) the ways the two things are alike are listed. In the outer circles, the things that make them different are included.

On the Venn diagram below, one writer compares and contrasts two cities- New York and Los Angeles. 


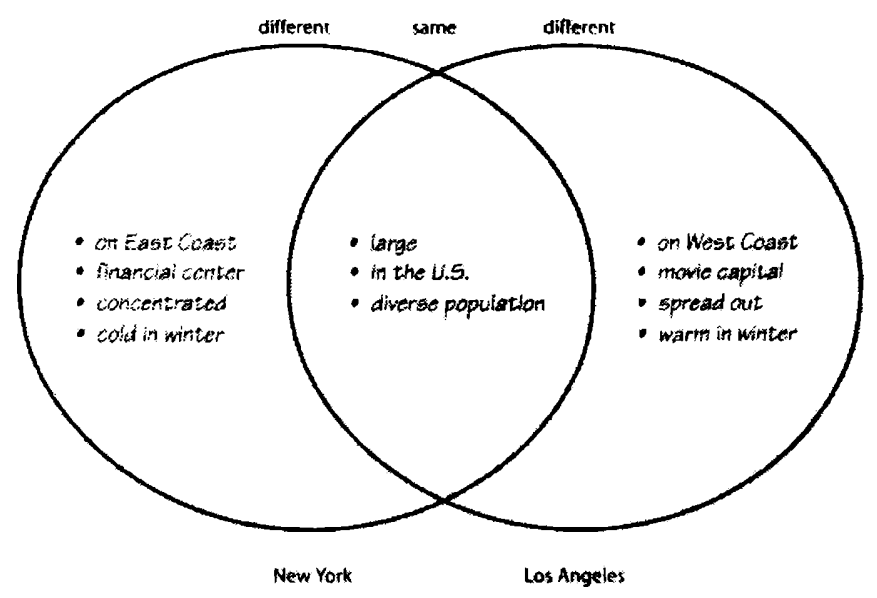

The Multicultural Workshop book 2

\section{USING VISUALS}

Pictures have had a role in language teaching and a wide range of visually-based material can be used in the teaching of writing. This again is a useful way to generate ideas for writing.

\section{Procedure}

Ask students to write down as many words as they can based on their response to the picture. When you think they are ready, get each student in turn to supply one or more of their words, and write them on the board, until all the ideas are exhausted.

- Discuss the words on the board. Compare and contrast them.

- Ask students to suggest what kind of writing they could now develop out of their ideas, what effect they would try to have on the reader and what, as readers, they would want to find in a piece of writing based on the picture concerned. Guide the discussion towards preparing students to start drafting a text based on their interpretation of and reaction to the picture.

\section{ORGANISING IDEAS}

Some writers prefer to organise their ideas before they start writing. Others prefer to get started by quickwriting and organise their ideas later. 
To organize ideas before writing, the learner can use the following strategies:

- Taking notes in a chart.

- Making an outline.

- Choosing a good title. Sometimes a title can help organise and focus ideas. Keeping a title in mind can help stay on track. A title also helps narrow down the topic.

\section{DEVELOPING A POINT OF VIEW}

Before writing, it is necessary to decide through whose eyes the topic is going to be viewed. For example, is the writer going to look at the topic through his own eyes? The eyes of a friend? A parent? Someone else? The point of view shapes the writing.

\section{UNDERSTANDING THE AUDIENCE}

The audience is the reader - the classmates, a friend, the teacher, or someone the writer does not even know. Before writing, it is important to have a clear idea of who the reader is. What is said in the writing and how the ideas are expressed will depend in part on the reader.

Before writing, answering these questions and keeping them in mind while writing can be a useful strategy:

- Who is going to read this piece of writing?

- What does my reader already know about the topic?

- Is the reader's background different from mine?

\subsection{LISTENING STRATEGIES}

\subsection{HOW DO LEARNERS FEEL ABOUT LISTENING TO ENGLISH?}

When we ask our students to think about their own attitudes towards listening to English, very often they say things such as: 

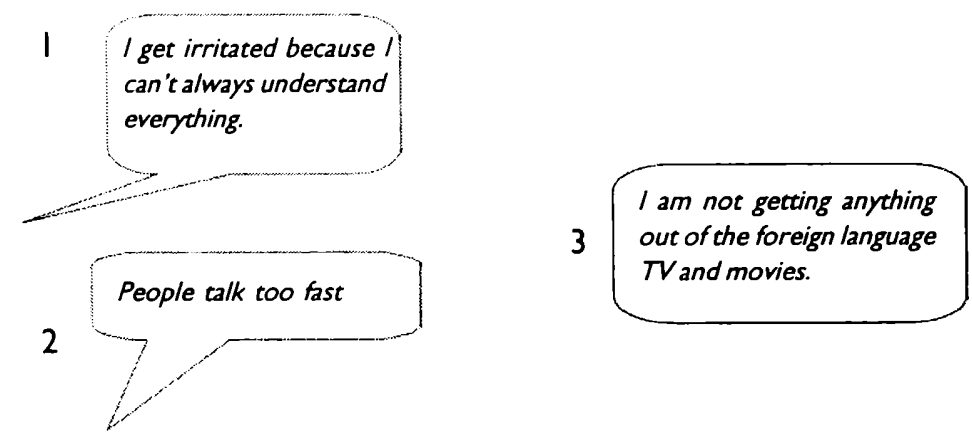

PROBLEM /

\section{GET IRRITATED BECAUSE I CAN'T ALWAYS UNDERSTAND EVERYTHING.}

Many language learners fail to realize that when they listen to their first language they do not actually hear every word. They also fail to appreciate that we integrate linguistic knowledge with our existing experience and knowledge of such things as topic and culture, and do not need to hear every word. This means that learners often have unrealistic expectations and try to understand every word of a listening text.

Learner's anxiety can be exacerbated by a classroom procedure which does not contextualize the text or prepare the topic by activating prior knowledge; in other words, a procedure which asks students to 'Listen to the text and then answer the questions.' This tests listening ability rather than aiming to teach it. Adults returning to English language learning whose earlier experiences have been of this nature may well have developed negative perceptions of their ability as listeners and a major task for the teacher will be to build confidence.

\section{POSSIBLE SOLUTION:}

The teacher should recognise this anxiety and provide positive classroom experiences.

For example, the teacher needs to make sure that the pace and length of a listening activity is not too taxing as the concentration required in trying to comprehend unfamiliar sounds can be tiring. 


\section{PEOPLE TALK TOO FAST}

If your students feel that they cannot follow their conversational partner, ask them to try some of the following techniques, which will allow them to take charge of the situation.

\section{POSSIBLE SOLUTIONS:}

LET THE SPEAKER KNOW THAT YOU ARE NOT FOLLOWING. If you don't understand a word or phrase, ask the speaker what it means. Learn how to say such phrases as 'What does ... mean?' or 'I don't know what ... means'.

ASK FOR REPETITION. Ask your partner to repeat what he or she just said. Learn phrases such as 'Please repeat' and 'What did you say?'

ASK YOUR CONVERSATIONAL PARTNER TO SLOW DOWN. Ask your partner to speak more slowly. Learn how to say 'Please speak more slowly'.

SEEK CLARIFICATION. If you did not get part of the message, ask additional questions. For instance, 'Sorry, I didn't catch that' or 'Could you repeat that, please?'

REPHRASE. If you are not sure that you have correctly understood what someone said, rephrase the speaker's message as best you can. For instance, 'Do you mean ...?' or 'Are you saying ...?'

PAY ATTENTION TO INTONATION AND TONE OF VOICE. Intonation may give you clues as to whether the utterance you heard was a statement or a question. On the other hand, tone of voice can tell you whether the speaker is pleased, angry or happy.

ASSUME THAT THE HERE AND NOW ARE RELEVANT. Assume that what a person says is directly related to something he or she is experiencing at that very minute. Most conversations relate to the present. People commonly talk about the weather, the social setting, their feelings (which are often obvious from their facial expressions), or some action that is under way. So it is very easy to establish the topic even if you do not

\section{6 / Cuadernos de lenguas Modernas}


I AM NOT GETTING ANYTHING OUT OF THE FOREIGN LANGUAGE TV AND MOVIES.

If your students feel identified with this comment, they should try to take control of their listening by trying to actively anticipate what they are likely to hear. The key word is prediction. Ask your students to try some of the following prediction strategies, and decide which most help them understand.

\section{STRATEGIES:}

USE YOUR BACKGROUND KNOWLEDGE. Anticipate information in a segment by relying on your knowledge of what such a segment is likely to contain. For instance, if you are watching an interview with a violinist, you may predict that the questions will have to do with the artist's training, favourite composers, future plans, etc. If it is a commercial, then it will probably contain information about the product and its qualities. After deciding what information the segment might address, watch it the second time to find answers to these questions. This will also help you anticipate specific words/ phrases that might be used.

USE VISUAL CLUES. Try watching with the sound off. This will allow you to concentrate on the visuals, noticing such clues as the setting, the action, the interaction, facial expressions, and gestures. These, in turn, will help you get a general idea of what is going on. Watch the segment again with the sound on to verify if your guess was correct.

USE INFORMATION FROM THE SEGMENT ITSELF. What you already know about the characters, the setting, and/or the story line of an episode may help you predict what is likely to logically happen next. In turn, this will help you anticipate what is likely to be said.

DETERMINE THE GENRE OF THE SEGMENT. Knowing the genre of a segment will help you determine how best to approach it. For instance, if it is an interview, then concentrate on the questions. If it is a news report, a who, when, where strategy will work best. If it is a drama, look for the story line. 
LISTEN TO FAMILIAR ELEMENTS. In listening to individual words, it may help if you first watch to determine the subject. Then your ability to hear individual words will grow. For example, if you know that the programme includes a travel segment, you may find yourself recognising the names of countries.

LISTEN TO FAMILIAR-SOUNDING WORDS. Many of these are 'international' words that occur in a number of languages or cognates.

LISTEN TO AND JOT DOWN REPEATED WORDS/ PHRASES. Unfamiliar words or phrases may be repeated several times. Sometimes, repeated use will help you infer a word's meaning from context. At other times, repetition will allow you to remember the word or phrase long enough to ask someone what it means or to jot it down so that you can look it up in a dictionary.

LEARN TO RECOGNISE NUMBERS AND PROPER NAMES. Most news reports contain references to people and places. It helps to know some typical names of people and what some geographical names sound like in the foreign language.

Recognising numbers will help you understand a telephone number, an address over the phone, a price in the store or the temperature on the weather report.

KEEP LISTENING. Understanding something is better than nothing at all. If you continue listening, chances are that you will comprehend at least some parts of the message. If that is not the case, you are probably listening to something that is too difficult for you.

\subsubsection{STRATEGIES TO DEVELOP LISTENING COMPREHENSION}

In terms of listening for comprehension, how can classroom practice rehearse the kinds of listening purposes and situations that learners will experience outside the classroom? How can we help learners build confidence in dealing with authentic spoken English? What kinds of classroom procedures will develop listening ability?

In order to answer these questions, we need information about what happens during the process of listening. It is clear for most of us that both participatory listening (as in face-to-face conversations and meetings) and non-participatory listening (as in listen- 
But recent research suggests ways in which teachers can help learners to become good listeners through the design of classroom procedures.

It has now become standard practice to use the following procedure when dealing with a listening text in class:

- The teacher and the students prepare for the listening in a number of ways. Various activities are used to help students to become familiar with the topic, to be exposed to some language features of the text and to activate any relevant prior knowledge they have. The teacher's role is to create interest, reasons for listening, and the confidence to listen.

Before setting the students to do a while-listening task, the teacher makes sure that they have all understood what it involves, e.g. filling in a chart.

- The students carry out the task independently without intervention from the teacher. Although the listening itself is done individually, students can be encouraged to check their responses in pairs or groups as soon as they are ready.

- In a feedback session, the teacher and students check and discuss the responses to the while-listening task. The teacher's role is to help students see how successful they have been in doing the task.

- Follow-up activities can be of various kinds, but at this stage the teacher may well wish to focus on features of the text or on bottom-up processes which will assist further development of effective listening.

A brief review of current course material will show that a repertoire of strategies exists for the pre-listening phase.

\subsubsection{STRATEGIES WHICH CAN BE USED IN THE PRE-LISTENING PHASE}

- Predicting content from the title of a talk.

- Discussing the topic.

- Agreeing or disagreeing with opinions about the topic.

Some topics lend themselves to pre-listening activities which require learners to form 
Some topics lend themselves to pre-listening activities which require learners to form an opinion. In this case a useful task is to invite students to make explicit their opinions to each other in class discussion and then listen in order to see whether or not these are similar to those in the listening material. This kind of activity reflects the natural ways in which we react to what we hear and also introduces relevant vocabulary and structures.

\subsubsection{STRATEGIES WHICH CAN BE USED IN THE WHILE-LISTENING PHASE}

While learners listen, they need to be involved in an authentic purpose for listening and encouraged to attend to the text more intensively or more extensively, for gist or for specific information. Learner activity can involve following the information, responding to attitudes expressed, reflecting on what is said, taking general notes, or writing down specific points.

The following table shows a list of some of the most important listening strategies, along with examples.

\begin{tabular}{|l|l|}
\hline STRATEGY & EXAMPLES \\
\hline Listening for gist & $\begin{array}{l}\text { Is the speaker describing a holiday or a day in the office? } \\
\text { Is the radio report about news or weather? }\end{array}$ \\
\hline Listening for purpose & $\begin{array}{l}\text { Are the speakers making a reservation or ordering food? } \\
\text { Is the speaker agreeing or disagreeing with the suggestion? }\end{array}$ \\
\hline Listening for main idea & Did the speaker like or dislike the movie? \\
\hline Listening for inference & What are the speakers implying by what they said? \\
\hline $\begin{array}{l}\text { Listening for specific informa- } \\
\text { tion }\end{array}$ & How much did they say the tickets cost? \\
\hline $\begin{array}{l}\text { Listening for phonemic distinc- } \\
\text { tions }\end{array}$ & $\begin{array}{l}\text { Did the speaker say first or fourth? } \\
\text { Did the speaker say they could or can't come to the party? }\end{array}$ \\
\hline $\begin{array}{l}\text { Listening for tone/ pitch to } \\
\text { identify speaker's attitude }\end{array}$ & $\begin{array}{l}\text { Did the speaker enjoy the wedding or not? } \\
\text { Is the speaker surprised or not? }\end{array}$ \\
\hline $\begin{array}{l}\text { Listening for stress } \\
\text { What is more important, where he bought the watch or when? }\end{array}$ \\
\hline
\end{tabular}




\section{POST- LISTENING ACTIVITIES}

Post- listening activities can take students into a more intensive phase of study in which aspects of bottom-up listening, such as discriminating between phonemes, finding the stressed syllable, recognizing fast speech forms, etc. are practised.

Post- listening work can also involve integration with other skill development of the topic into reading, speaking, or writing activities.

\subsection{STRATEGIES IN SPEAKING ENGLISH}

Perhaps the first question to ask is what reasons we have for asking our students to practise speaking in the classroom. There could be several answers. One is that, for many students, learning to speak competently in English is a priority. They may need this skill for a variety of reasons. But learning to speak competently is a complex task.

As communicative approaches have developed, teachers have been concerned to ensure that students not only practise speaking in a controlled way in order to produce features of pronunciation, vocabulary, and structure accurately, but also practise using these features more freely in purposeful communication. It has therefore become usual to include both accuracy- and fluency-based activities from the beginning of the course.

However, there are many more aspects to conversation than these. Studies of native speaker conversation have provided with insights into what is involved in terms of managing interaction. For example, there are skills relating to opening and closing conversations, to the sharing of time, to taking turns and contributing both longer and shorter turns as appropriate, to attending to and responding to one's interlocutor, and to interrupting. If any of these are lacking or poorly performed, then communication can break down. And the reasons for the breakdown may be lack of language to undertake these skills effectively or differences in the cultural conventions associated with them.

The challenge for the communicative classroom is to find activities that develop strategies for speaking in order to prepare students for spontaneous interaction. 
Comments:
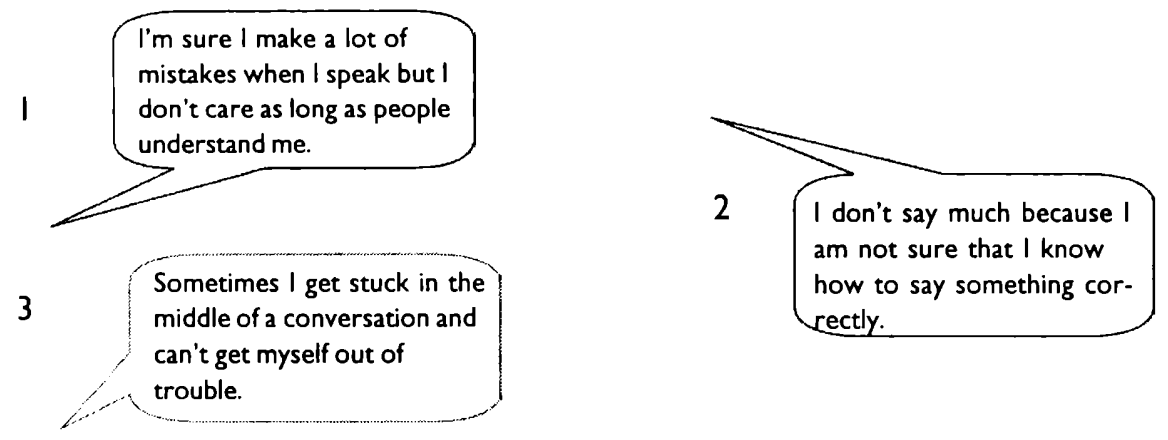

These are the typical comments of learners who try to express what they want to say but lack the vocabulary and structures they need. Their solution is to use communication strategies. There is a field of research which has tried to categorise these. Faerch and Kasper (1983) have made the distinction between avoidance behaviour, in which learners try to eliminate a problem by changing the topic or not participating in a conversation, and achievement behaviour, in which ways are found to cope with the problem, for example: switching to the first language; word coinage, -often influenced by the first language-; restructuring ('I have two ... I have one brother and one sister'); a direct appeal for help from the listener (It's ... what is this colour?'); and gesture (for example, pointing in the previous example).

Perhaps the most important implication for the teacher is simply to appreciate and understand what is happening when students use communication strategies, as they are likely to do in fluency activities which push them to the limits of their language resources. Communication strategies can be indicators of gaps and uncertainties in language knowledge, and can play a role in the teacher's decisions about what to focus on in feedback.

Clearly the advantages of using achievement strategies or taking risks with the language is that they keep the conversation going and may encourage the listener to pro- 
vide the necessary language.

The question arising is whether communication strategies can be trained. Certainly teachers can help students early in a language programme by teaching them appropriate questions for requesting help, for example 'What does this mean?' and 'How do you say...?' and the language to ask for vocabulary items, for example 'What do you call a person who...?'. Whether or not a teacher believes that communication strategies can be taught, it is certainly worth exhibiting positive attitudes towards achievement behaviour and encouraging it.

The other way in which learners work to make themselves understood is through negotiation of meaning. For example the speaker may produce an indistinct or inaccurate message, as in:

A: You mustn't come except you bring the children.

B: I'm sorry, shall I bring my children?

Speakers need an ability to negotiate, until the meaning is clear. Part of this will involve using achievement strategies, such as paraphrase or gesture, to explain things more clearly. It is therefore useful for teachers to teach the language that will help with negotiation of meaning and to do this early in a course. Most importantly, of course, learners need opportunities for practice. Certain kinds of fluency activities may be better than others in providing these opportunities.

\section{STRATEGIES FOR LEARNING VOCABULARY}

Nunan's typology of learning strategies includes some of the strategies used for learning vocabulary (classifying, for instance). However, I would like to present in this section other options that teachers have to assist students in developing their vocabulary strategies. The activities chosen have been extracted from recently published textbooks.

WORD CLUSTERING. This strategy will allow students to make connections between new and known items as well as semantically related words. Examples of creative groupings include: 
- clusters of topically related lexical items. Example:

Complete the following networks.
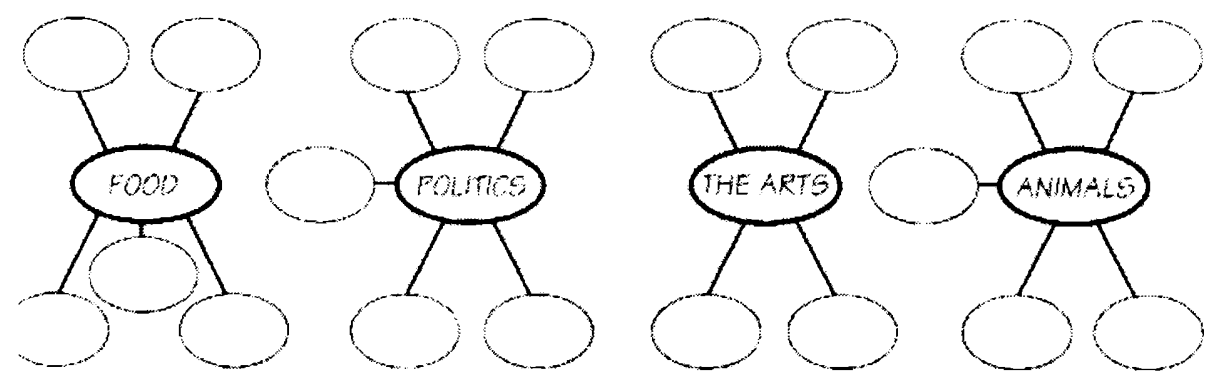

Make two other networks to help you to learn the words on the opposite page.

English Vocabulary in Use. (Page 33)

- pairs of logically linked adjectives and nouns or verbs and nouns. Example:

Look at the complete word forks below. Finish the others.

\begin{tabular}{l|l|l|l|l|l|l|l|l|l|l}
\hline original & & & shoot & & & magnificent & & & kick & \\
\hline brilliant & & & edit & & & breathtaking & & & hit & \\
\hline unusual & idea & & direct & a film & & superb & view & & bounce & a ball \\
\hline great & & & star in & & & & & & & \\
\hline excellent & & & review & & & & & & & \\
\hline
\end{tabular}

English Vocabulary in Use. (Page 5)

- pairs of synonyms and antonyms. Example:

$$
\text { Urban } \neq \text { rural } \quad \text { stop }=\text { cease (more formal) }
$$

English Vocabulary in Use. (Page 6) 
- semantic groupings. Example: word tree
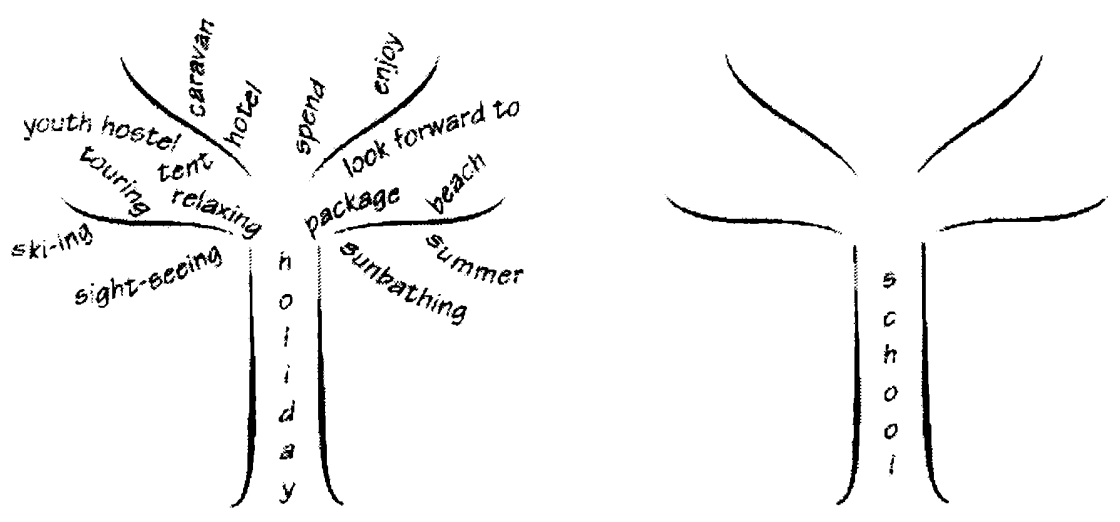

English Vocabulary in Use. (Page 5)

- pictures and diagrams. Example.
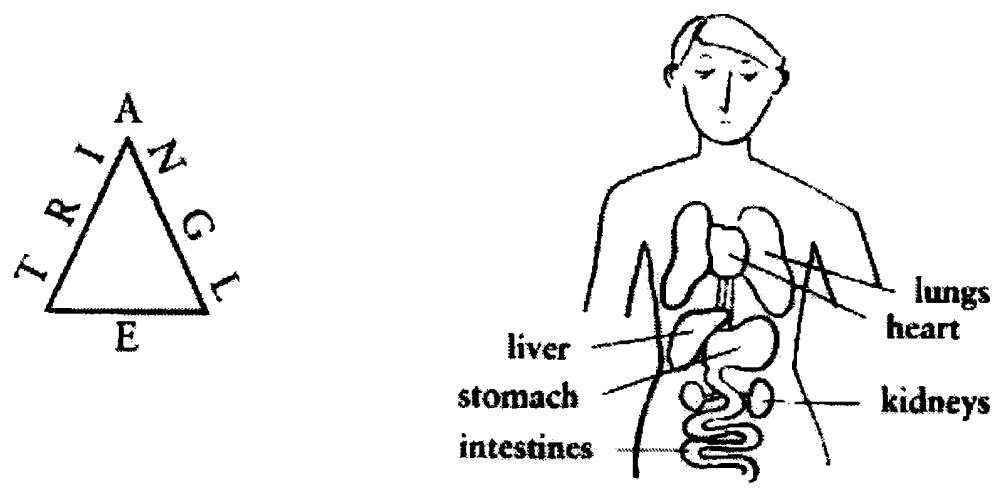

English Vocabulary in Use. (Page 4) 
word classes. Making tables for word-classes is a good idea , since learners can fill in the gaps over time.

\begin{tabular}{|c|c|c|c|}
\hline noun & verb & adjective & person \\
\hline production & produce & & producer \\
\hline industry & 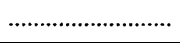 & industrial & \\
\hline export & 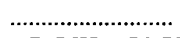 & 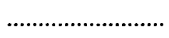 & 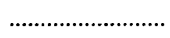 \\
\hline
\end{tabular}

English Vocabulary in Use. (Page 7)

Using imagery. To form a mental image of a word by associating it with its colour, size, smell or any other physical characteristic. For instance when trying to remember names of vegetables and fruits, you can associate some with being red and round and others with being long and green.

\section{GUESSING THE MEANING OF WORDS FROM CONTEXT.}

In any passage, there are a few words whose meaning could be inferred from context, provided that the learner is willing to consider the available clues.

For instance, a learner might deduce from the syntactic structure that a word is an adjective because it is located before a noun, he might divide the word into its parts, realizing that '-able' is a common suffix for an adjective, he might read on for evidence in the context of the text that the meaning is positive, or he might look for a similar word in his own language. In this way contextual clues which relate to the reader's knowledge are used for inferencing meaning.

Some of these strategies are called metacognitive. They are not direct mental operations, but indirect strategies which facilitate learning by actively involving the learner in conscious efforts to remember new words.

Among metacognitive strategies we may include the following: consciously collecting words from authentic contexts; making word cards; categorising words into lists; and reactivating vocabulary in internal dialogue.

- MAKING WORD CARDS. This strategy requires the student to find out a fair amount of information about each word and to write it on an index card in the following manner: 
Write the word.

Write its pronunciation.

Copy any related family words.

Copy the sentence containinig the word from the text.
Copy the definitions of the word.

If a verb, note the grammar structures that can follow it.

Copy any synonyms.

Write your own sentences using the word.

Taken from Aebersold and Field (1997), From Reader to Reading Teacher, CUP. (page 152)

When used regularly, this is an effective way of learning vocabulary. It is fluid and individualised, allowing students to be in charge of their own learning.

No matter how much direction teachers provide to help students learn vocabulary in class, the final responsibility for learning new words rests with the students. It is useful for the teacher to be aware of the variety of strategies used by learners to cope with words, to encourage learners in effective strategies, and to introduce some of these through teaching.

\section{CONCLUSION}

Education is a lifelong process, one purpose of which is to equip learners to cope in a changing world. As Knowles (1976:23) similarly reminds us, one of our main aims in education is 'helping individuals to develop the attitudes that learning is a lifelong process and to acquire the skills of self-directed learning'.

For teachers, learning more about the complexities of learning, both cognitive and affective, can also help our professional growth and personal satisfaction. A teacher who truly understands the importance of affect in the classroom, and who believes that all students can learn, can offer opportunities for success to all students (Guild 1994). Teachers also have the responsibility to ask students about their learning strengths and then to listen.

Language teaching is a complex endeavour, requiring a professional approach which 
involves decision-making at a number of levels. Teachers are not merely agents in an educational hierarchy, but have the creative responsibility of building links between externally imposed curriculum objectives and their own course planning, activity design, materials development, and management of learning procedures. We are involved in a process of continuing professional self-development. Teachers play an important part in fostering the right climate for effective learning to take place, for building learner's confidence, for people's individuality to be respected, for developing appropriate learning strategies and for moving towards learner autonomy.

Some learners come to the task of learning a foreign language with the expectation of being active learners, but others come ill-equipped. For the latter group, perhaps the most useful service the teacher can perform is to encourage them in positive attitudes and prepare them in effective strategies. This preparation implies a change in perception about what language learning involves and a change in the expectation that language can only be learned through the careful control of a specialist teacher. It also involves acquiring a range of techniques with which learners can enhance their learning.

Raising student awareness in the language learning process can provide the scaffolding for more effective and efficient learning. A broad understanding of learning environments, learning styles and learning strategies can allow students to take control of their learning and maximise their potential for learning. Asking students to evaluate their language learning experiences and to be accountable for their own learning increases their sense of both freedom and responsibility. Students need time to investigate and experience resources that enable them to experiment and discuss, and they need the opportunity to evaluate what they are learning about learning. Moreover, students can comprehend how learning processes occur, what choices they have in these processes, and how they can identify their learning strengths and weaknesses. The result can be educated students who are able to participate fully in society, both freely and responsibly; students ready for change. 


\section{APPENDIX}

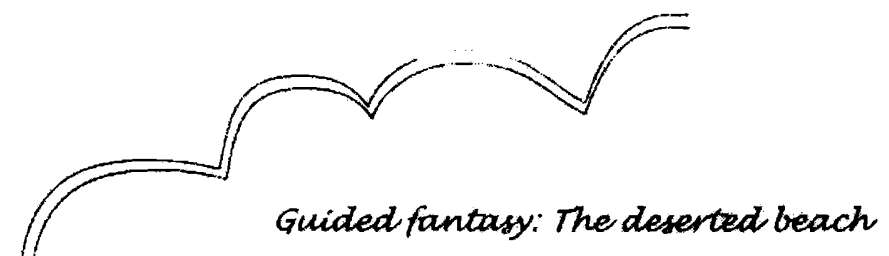

Make sure you're sitting in an upright position with both feet flat on the floor, hands resting comfortably on your thighs. Take a deep breath, and relax.

Close your eyes for a moment, and imagine that you are walking alone along a deserted beach you are very safe and will not be disturbeds

Make a clear picture in your mind's eye Look around you as you walk. What can you see? Notice the colours: Look out to sea as far as the horizon Is the sea calm? Is it roughe Are there any boats? or birds? What kind of day is it? Sunny? Cloudy?

Hear the sound of the waves. Hear the sound of your footsteps in the sand or on the pebliles: What other sounds are you anvere of can you hear seagulls?

Feel the air against your skin Breathe it ins How doer it mell? How does it taste? feel the movement of your body as you walke feel the beach under your feet.

Go right up to the water's edge and put your hand into the water. How does that feel? put your wet hand against your face. Is it colds can you smell the seas Can you taste the salt?

You may feel like taking off your thors and socks to have a paddles or you may feel like taking off the rest of your clothes to have a swimu or you may feel like sitting for a while and gazing out to sea or you may feel like continuing your walk along the beach. Do whatever you feel lcke doing. You will have half a minute of real time which is all the time you need. And, whatever you do, be very aware of everything that you see and hear and feek And be glad to have this chance to be alone in such a beautrful place..

And now prepare to leave, knowing you can revisit this place any tame you choose. When you' re ready, take a deep breath, and, with a sense of gladness, come back to the roome
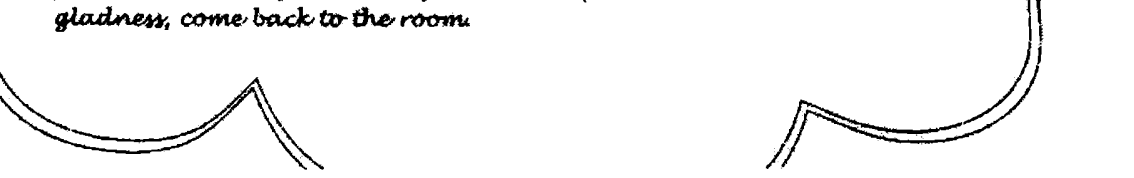

Taken from Revell, Jane and Norman, Susan (1997), In Your Hands NLP in ELT, London, Saffire Press. 


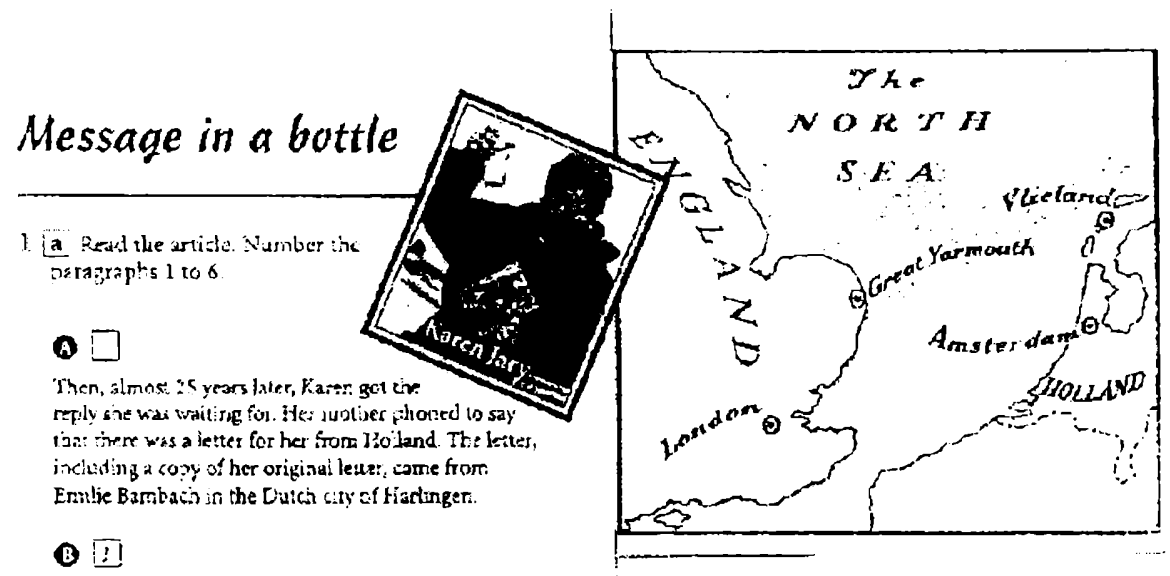

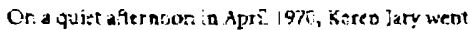

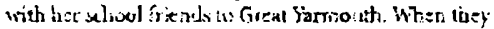
sot to the beach they each pul a arefisilo.writsen ietre: inic 2 botrie and threw it in:o the North Se3.

C Li

In her Seller Ecilie said thal st:e lounc: tom hortie in

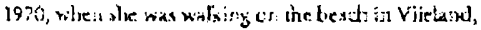

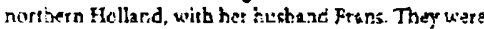
on theis horey roon.

(D)

"he lieje gar:" is now 36 and named with mo

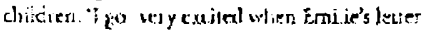

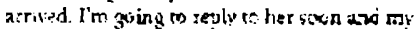
daugh:e: saye sine sourg to writ: io Emale's youngest sor.' Ervilie also said. 'l'in luaping to ga "o Enyland to meel karen ard ber family: I'rr. sure I'll zet on with hac verg well:

(B)

"Iher: the letter gor lost is the house. I lockied fo: it ever ywhere, but 1 driv' : find It satil thus Christmas, 2. . yeass listet. when I wes clearing the attic. I decided so

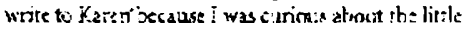
gist liat wrute :lie lester:

\section{C}

E'evea-year 0 d karen wis siure bhat somstody was going to find be: measege in e bottle. Her letter, addressed to 'Star Reader', was in a Hiro kelihus? burto Sul ciaps passed, thell werks. then monuts, and karen dieg'a' get as arswer. Finaliy she forgot atout her letter, unti lat week...

Taken from Oxenden, Clive; Seligson, Paul and Lathan-Koenig, Christina (1997), English File 2, Oxford, Oxford University Press. 
(1) File 7 [6. Lubel the picture with five of the ivords.

rasterway no:e island despair (n) sea lonely (adj)

mend ( $b$; shore rescue

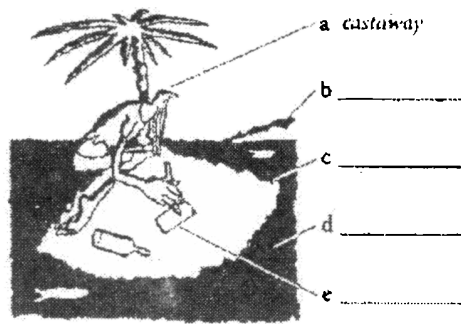

2 Makch the other words to the definitions

1 the feeling when you have no hope

2 alone and sad

3 another way of saying repoit

4 help somebody who is in danger

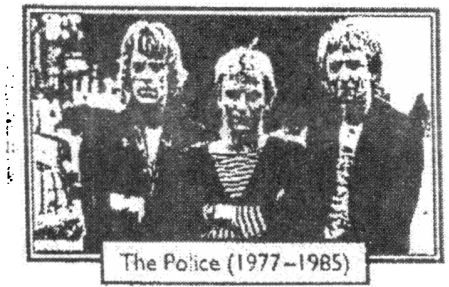

THE POLICE

- formed in 1977 were Sting (real name

Gordori Sumner), Andy Summers

- (gultar), and Stewart Copeland (drums).

BBC radio didn't play their first singles

because they were about prostiturion,

Roxanine and teenage suiclde, Con't stond

Losing You. Messoge in a Bottle was No.!

all around Europe in 1979. The group

separated in 1985. As a solo artist Sting

has sold more than 50 million records. histen and complote with the words.

\section{Message in a bottle 1977}

just a 'castaway

$2 \mathrm{An}^{2}$ lost at ${ }^{3}$

Another day

i Na one here but me

More loneliness

5 Than any man could bear me before I fall into ${ }^{*}$

\section{Chorus}

s'lll send an SOS to the world

ill send an SOS : to the world

10 I hope that someone gets my

I hope that someone gets my

1) I hope that someone gers my

Message in a bottle

i" A year has passed since I wrote my ${ }^{\top}$

But I should have known this right from the scart

is Oniy hope can keep me cogether Love can your life

is But love can break your heart

\section{Chorus}

Walked out this morning

3) Don't believe what I saw

A hundred billion bottles

2: Washed up on the?

Seems lim not alone in being alone

24 A hundred billion 10 $s$

Looking for a home

\section{Chorus}

is Sending out an SOS 1

Sending out an SOS: etc.

\section{Glossary}

loneliness = the noun from lonely bear = accept without complaining SOS = (Save Our Souls) a message asking for help

Taken from Oxenden, Clive; Seligson, Paul and Lathan-Koenig, Christina (1997), English File 2, Oxford, Oxford University Press. 
- Aebersold, Jo Ann and Field, Mary Lee (1997), From Reader to Reading Teacher, Cambridge, Cambridge University Press.

- Arnold, Jane. (1999), Affect in Language Learning. Cambridge. Cambridge University Press..

- Bruner, J. S. (1960), The Process of Education. Cambridge, Mass: Harvard University Press.

- Chamot, O’Malley (1987) In Learning Strategies in Second language Acquisition, Cambridge, Cambridge University Press. 1990.

- Ellis, Gail and Sinclair, Barbara (1999), Learning to Learn English, Scotland, Cambridge University Press.

- Faerch, C. and Kasper, G. (1983), Strategies in Interlanguage Communication. London, Longman.

- Feuerstein, R. (1991), In Psychology for Language Teachers. Op.cit.

- Guild, P. (1994), In Affect in Language Learning. Op cit

- Hamachek, D. (1977), In Psychology for Language Teachers. Op.cit

- Harmer, Jeremy (1991), The Practice of Eng/ish Language Teaching. London. Longman.

- Handy, C. (1989), The Age of Unreason. Penguin.

- Knowles, M. (1976). The Modern Practice of Adult Education. New York, Association Press.

- Nunan, David (1988), The Learner-Centred Curriculum, Great Britain, Cambridge University Press.

- Nunan, David ( 1999), Second Language Teaching and Learning, USA, Heinle \& Heinle Publishers.

- O'Malley, J. Michael and Chamot Anna Uhl (1990), Learning Strategies in Second language Acquisition, Cambridge, Cambridge University Press.

- Oxford, Rebecca (1990), Language Learning Strategies: What every Teacher Should know, Boston, Mass. Heinle \& Heinle Publishers.

- Rogers, C.R. (1969), Freedom to Learn. Columbus, Ohio, Charles Merill.

- Rubin, Joan (1975), 'What the "good language learner" can teach us.' TESOL Quarterly 9: 4I-5I.

- Rubin, Joan and Thompson, Irene (1994), How to be a more successful language learner, USA, Heinle \& Heinle Publishers.

- Savater, Fernando (1997), El valor de educar, Barcelona, Ariel. 
- Stoller, F. (1986). Teaching Second Language Reading for Academic Purposes. Reading MA..

- Toffler, A. (1970), Future Shock. London. Bodley Head.

- Vann, R. and Abraham, R. (1990), Strategies of unsuccessful language learners. TESOL Quarterly 24, 2: 177-98.

- Wenden A. and J. Rubin (1987), Learner Strategies in Language Learning. Hemel Hempstead. Prentice Hall.

- Williams, E (1984), Reading in the Language Classroom. London and Basingstoke. Macmillan.

- Williams, M. and R. Burden. (1997) Psychology for Language Teachers. Cambridge. Cambridge University Press..

\section{Bibliography for the examples of learning strategies:}

- Burke, Kathy ; Brooks, Julia and Rushton, Lynne (2000), Wavelength Elementary, London, Pearson Education Limited.

- Burke, Kathy ; Brooks, Julia and Rushton, Lynne (2000), Wavelength Pre-Intermediate, London, Pearson Education Limited.

- Cunningham, Sarah and Moor, Peter (1998), Cutting Egde Intermediate, Madrid, Longman.

- Cunningham, Sarah and Moor, Peter (1998), Cutting Egde Upper-Intermediate, Madrid, Longman.

- Garton-Sprenger, Judy and Greenall Simon (1991), Flying Colours, Students' book 2, Scotland. Heinemann.

- Lonon Blanton, L. and Linda Lee (1995), The Multicultural Workshop.Book I, USA, Heinle \& Heinle Publishers.

- Lonon Blanton, L. and Linda Lee (1995), The Multicultural Workshop.Book 2, USA, Heinle \& Heinle Publishers.

- Lonon Blanton, L. and Linda Lee (1995), The Multicultural Workshop.Book 3, USA. Heinle \& Heinle Publishers.

- Oxenden, Clive; Seligson, Paul and Lathan-Koenig, Christina (1997), English File 2. Oxford, Oxford University Press.

- Spratt, Mary (1989). Tuning in, England, Longman. 
Bibliography for the sample class:

- Oxenden, Clive; Seligson, Paul and Lathan-Koenig, Christina (1997), English File 2, Oxford, Oxford University Press.

- Revell, Jane and Norman, Susan (1997), In Your Hands NLP in ELT. London. Saffire Press.

- Sting, Message in a bottle 